\title{
A New Code for Spectrometric Analysis for Environmental Radiological Surveillance on Monitors Focused on Gamma Radioactivity on Aerosols
}

\author{
Alfredo de Blas, Member, IEEE, Albert Riego, Roger Garcia, Carlos Tapia, Javier Dies, Juan Toral, Enric Batalla, \\ and Pedro Diaz
}

\begin{abstract}
This paper presents a new code for the analysis of gamma spectra generated by an equipment for continuous measurement of gamma radioactivity in aerosols with paper filter. It is called pGamma and has been developed by the Nuclear Engineering Research Group at the Technical University of Catalonia - Barcelona Tech and by Raditel Serveis i Subministraments Tecnològics, Ltd. The code has been developed to identify the gamma emitters and to determine their activity concentration. It generates alarms depending on the activity of the emitters and elaborates reports. Therefore it includes a library with NORM and artificial emitters of interest. The code is being adapted to the monitors of the Environmental Radiological Surveillance Network of the local Catalan Government in Spain (Generalitat de Catalunya) and is used at three stations of the Network.
\end{abstract}

Index Terms-Environmental radiation, gamma activity, gamma spectrometry, isotope identification.

\section{INTRODUCTION}

$\mathbf{T}$ HE use of monitors with spectrometric capability in environmental radiological surveillance networks provides additional information that complements the ambient dose equivalent $H^{*}(10)$. Based on this premise, our group (Nuclear Engineering Research Group) at the Technical University of Catalonia - Barcelona Tech and Raditel Serveis i Subministraments Tecnològics, Ltd. have developed an equipment for continuous measurement and identification of gamma radioactivity in aerosols with paper filter. Gamma spectrum analysis allows the identification and determination of activity concentration of radiation sources. Excellent commercial software is available for this purpose (among others, GammaVision form ORTEC and Genie2000 from

Manuscript received May 27, 2015; revised October 12, 2015; accepted January 21, 2016.

A. de Blas, A. Riego, R. Garcia, C. Tapia, J. Dies, and P. Diaz are with the Nuclear Engineering Research Group, Department of Physics and Nuclear Engineering, Technical University of Catalonia, 08028 Barcelona, Spain (e-mail: alfredo.de.blas@upc.edu).

J. Toral is with Raditel Serveis, 43005 Tarragona, Spain (e-mail: raditelserveis@gmail.com).

E. Batalla is with the Radiological Activities Corrdination Service (SCAR) of the Generalitat de Catalunya, 08003 Barcelona, Spain (e-mail: ebatalla@gencat.cat).

Color versions of one or more of the figures in this paper are available online at http://ieeexplore.iee.org.

Digital Object Identifier 10.1109/TNS.2016.2521388 mode.

CANBERRA). Nevertheless, it is generic software not intended for automatic analysis since each individual analysis must be conducted by a specialised technician. For this reason, our research group has developed a spectrometric analysis code specifically designed for the above equipment. This code is being used at stations with aerosol monitors on the Environmental Radiological Surveillance Network of the Generalitat de Catalunya (local Catalan Government), Spain ${ }^{1}$ : Three monitors are currently fully operative: two in the surveillance station of the Ascó and Vandellòs Nuclear Power Plants (both in the province of Tarragona, Spain), and one in the Engineering School of Barcelona, Spain. Two new monitors will shortly be deployed in Roses (province of Girona) and in Puigcerdà (province of Barcelona). The code has been adapted for the analysis of gamma spectra generated by other monitors with spectrometric capability of the Network, i.e. river and direct air monitors. We are starting the tuning of these versions of the code on the monitors for river and direct air.

The code, called pGamma, discriminates spectrum information, identifies emitters appearing on the spectrum, determines activity concentration in $\mathrm{Bq} / \mathrm{m}^{3}$ and generates alarms according to its calculated values. It has a normal operation mode and special operation mode for spectra obtained during energy calibration of the equipment. Additionally, another mode called investigation, is set when the variation in the total number of counts exceeds a certain level, or when a full energy peak is not identified.

The code input is an ASCII text file with the number of counts per channel of the spectrum and a header with information about measurement conditions: date and time of counting initiation and termination, live time, air flow, operation mode, the parameters of the energy calibration curve, etc. Fig. 1 is a general operation diagram of pGamma in normal operation

The paper is organized as follows: Section II describes the treatment of the peaks in the spectrum. In Section III, efficiency calibration is presented. The determination procedure of activity concentration is shown in Section IV. Section V describes the identification of ${ }^{131}$ I. In Section VI, the action levels are

\footnotetext{
${ }^{1}$ This network is integrated in the Spanish Nuclear Security Council network.
} 


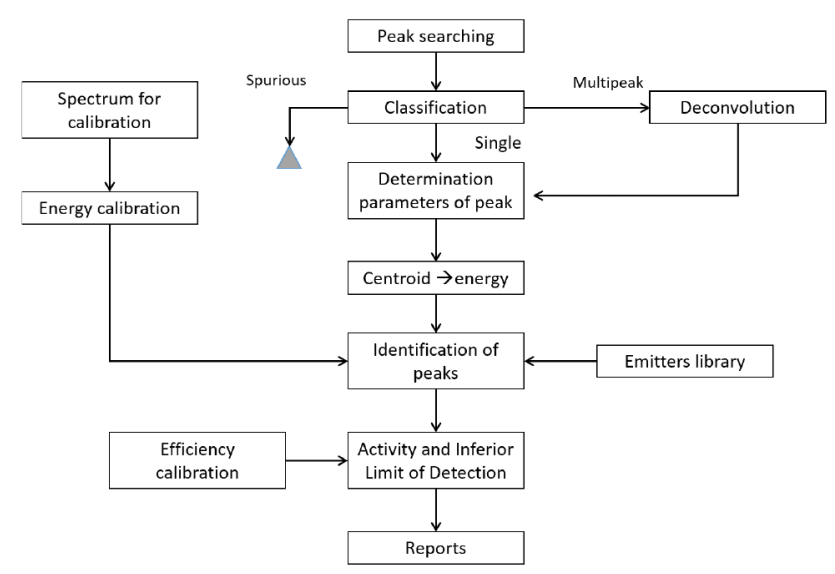

F1:1 Fig. 1. General diagram of pGamma.

presented. An Ascó station spectrum is analised in Section VII. Finally, conclusions are drawn in Section VIII.

\section{Peak Treatment}

The first step in the analysis of the spectrum is the treatment of the peaks: the searching of possible peaks on the spectrum and its identification.

\section{A. Peak Search}

Peak search and analysis is performed after the input spectrum is smoothed using the Savitzky-Golay method [1]. The smoothing algorithm allows the first, second and third derivatives of the spectrum to be obtained. The first derivative is used to determine the local maximums, which are subjected to a statistical test to discriminate real centrer of peaks (centroids) from spurious transitions. The nearest relative maximums of the first derivative at both sides of the centroid, indicate the channel of the peak boundaries. Using the second and the third derivate, single peaks are discriminated from multiplets. With the centroid and the boundaries of the peaks, the net area and the background are determined. The last step is the fitting of each peaks to a Gaussian curve. It allows the determination of the full width at half maximum (FWHM) and perform the chi-square test for further discrimination. With this information, pGamma generates a first list of possible peaks with their characteristics. The calculated parameters are centroid, lower and upper boundaries of the possible peak, full width at half maximum, gross area and net area.

\section{B. Peak Identification}

1) Energy Calibration: The use of energy calibration makes it possible to state the centroid, FWHM and limits of peaks in energy units instead of number of channels. The relationship between energy and adopted number of channel is:

$$
E=a+b C+c C^{2}
$$

Where $C$ is the channel and $a, b$ and $c$ are the parameters of the calibration curve. Energy calibration must be performed prior to installation of equipment in a station.
2) Peak Identification: Peaks can be identified using the 111 library of gamma emitters of interest included in the code. 112 This library has been created by us using information from [2]. 113 For aerosol equipment, these emitters are the NORM radionu- 114 clides $\left({ }^{238} \mathrm{U}_{-}{ }^{222} \mathrm{Rn}\right.$ series, ${ }^{232} \mathrm{Th}-{ }^{220} \mathrm{Rn}$ series, ${ }^{40} \mathrm{~K}$ and $\left.{ }^{7} \mathrm{Be}\right) \quad 115$ and artificial emitters from nuclear power plant discharges 116 (e.g. radio-iodines, ${ }^{137} \mathrm{Cs},{ }^{134} \mathrm{Cs}$ and ${ }^{132} \mathrm{Te}$ ) or industrial appli- 117 cations. Information about emitters includes energy and the 118 emission probability of emitted gamma rays, empirical thresh- 119 olds for NORM emitters to decide if pGamma must switch to 120 investigation mode and derived concentration limits in the air. 121

The centroid energy of each peak is compared with the 122 energy of gamma emitters. For similar values, the emitters are 123 considered candidates for that peak and a list of candidates 124 is generated. To identify a set of peaks with a radionuclide 125 with multiple gamma emissions, the ratio between intensity 126 of detected gammas and total intensity of the gammas of the 127 emitter in the library is used. The relationship between the 128 members of ${ }^{238} \mathrm{U}_{-}{ }^{222} \mathrm{Rn}$ series and ${ }^{232} \mathrm{Th}-{ }^{220} \mathrm{Rn}$ series is con- 129 sidered too. pGamma cannot determine activity concentration 130 of unidentified peaks.

\section{Detection EFFiciency CALibRation}

In order to determine activity concentration, the code needs 133 information about the detection efficiency. Since the factors 134 integrating the detection efficiency are very difficult to deter- 135 mine due to a complex geometry and a wide range of possible 136 energies, efficiency calibration must be performed. First, the 137 same geometry of the paper filter (source), detector and detec- 138 tion volume of the equipment during normal operation must 139 be reproduced. This implies preparing a calibration source 140 by shaping it into a disc with the same diameter of aerosols 141 retained on the filter, and the same self-absorption (negligi- 142 ble) and gamma emitters of several energies in the range from 143 $100 \mathrm{keV}$ to $2000 \mathrm{keV}$. In consequence, the analytical determi- 144 nation of efficiency is cumbersome. The solution consists in 145 using a calibration source with similar characteristics to the 146 source to be measured and determining efficiency from experi- 147 mental values. To ensure unbiased calibration, the calibration 148 source should be identical to the radioactive samples in all 149 aspects affecting detection [3]. If no calibration source is avail- 150 able or more points are required for adjusting the efficiency 151 curve, Monte Carlo n-Particle (MCNP5, version 2.6.0) provide 152 a further possibility for calculating the detector efficiency. 153

We used simulated ${ }^{131} \mathrm{I}$ and commercial ${ }^{60} \mathrm{Co}$ sources 154 (Table I) with similar geometry and materials to those of the 155 impregnated filter of the monitor. The simulated ${ }^{131}$ I source 156 is composed of two radioisotopes: ${ }^{133} \mathrm{Ba}$ and ${ }^{137} \mathrm{Cs}$. The com- 157 bination of both emitters generates a gamma energy spectrum 158 whose full energy peaks have centroids and a relationship of 159 areas very similar to the ${ }^{131} \mathrm{I}$ spectrum. The simulated ${ }^{131} \mathrm{I} 160$ source has the same area as the impregnated filter. The emitter 161 material is deposited on a polymeric membrane with a stainless 162 steel backing of $0.762 \mathrm{~mm}$ thickness and an $0.9 \mathrm{mg} / \mathrm{cm}^{2}$ alu- 163 minized mylar window. Gamma absorption of the window and 164 the backscattering on the back of the membrane are negligible. 165 Therefore, it can be considered that the material and geometry 166 
CHARACTERISTICS OF THE CALIBRATION SOURCES (REFERENCE FOR ACTIVITY: 01-JANUARY-2014)

(a)

\begin{tabular}{cc}
\hline Nuclides & ${ }^{137} \mathrm{Cs},{ }^{133} \mathrm{Ba}$ \\
${ }^{137} \mathrm{Cs}$ Activity & $0.4096 \mathrm{kBq}$ \\
${ }^{133} \mathrm{Ba}$ Activity & $4.222 \mathrm{kBq}$ \\
${ }^{131}$ I Activity & $3.684 \mathrm{kBq}$ \\
Manufacturer & Eckert \& Ziegeler \\
Model & EAB-131(s)-PL \\
Source No. & K9-928 \\
\hline
\end{tabular}

(b)

\begin{tabular}{cc}
\hline Activity & $3.863 \mathrm{kBq}$ \\
Manufacturer & Eckert \& Ziegeler \\
Model & EAB-060-PL \\
Source No. & K9-925 \\
\hline
\end{tabular}

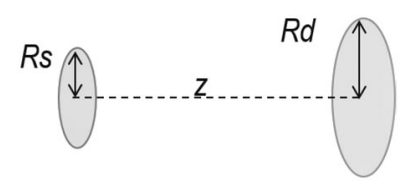

F2:1

of the source have the same behaviour as the impregnated paper filter. To simulate the detector response on the MCNP5 simulation we had used the FWHM obtained from the peaks on the spectra for the calibration sources $\left({ }^{131} \mathrm{I}\right.$ and $\left.{ }^{60} \mathrm{Co}\right)$ with the experimental setup. The function used is:

$$
F W H M=0.008+0.013 \cdot \sqrt{E+0.593 \cdot E^{2}}
$$

where $\mathrm{E}$ is the energy in $\mathrm{MeV}$ and the FWHM obtained is also in $\mathrm{MeV}$.

Experimental efficiencies were obtained by analyzing the experimental spectra of ${ }^{131} \mathrm{I}$ and ${ }^{60} \mathrm{Co}$ by pGamma. Before the calculation of the efficiency, the net counts of the experimental peaks had to be compensated by a correction factor. The source capsule elevated the membrane where the radioactive material is deposited such that the membrane is slightly higher than the paper filter (about $0.283 \mathrm{~cm}$ ). Assuming that both sources, the impregnated paper filter in normal operation and the calibration source, are discs and the detector window is a disc too (geometry on Fig. 2), we could determine the geometric factor in both cases using the following expansion in power series:

$$
\begin{aligned}
g f_{i}= & \frac{1}{2}\left(1-\frac{1}{R}\right)-\frac{3 \cdot \omega^{2} \psi^{2}}{16 \cdot R^{5}} \cdot\left[1-\frac{5 \psi^{2}}{6 \cdot R^{4}} \cdot\left(1-\frac{3 \cdot \omega^{2}}{4}\right)\right. \\
& \left.+\frac{35 \cdot \psi^{4}}{48 \cdot R^{8}}\left(1-\frac{5 \cdot \omega^{2}}{2}+\frac{5 \cdot \omega^{4}}{8}\right)+\cdots\right]
\end{aligned}
$$

the factors $R, \psi$ and $\omega$ are determined as:

$$
\psi=\frac{R_{S}}{z} ; \omega=\frac{R_{d}}{z} ; R=\sqrt{1+\omega^{2}}
$$

where $R_{S}$ is the source radius, $R_{d}$ is the detector radius, $z$ is the distance between the source and the detector. Equation (4) can
TABLE II

EXPERIMENTAL DETECTION EFFICIENCY

\begin{tabular}{ccccc}
\hline Peak & $E_{i}(\mathrm{keV})$ & $N_{i}(\mathrm{cps})$ & $S_{i}(p h / s)$ & $\varepsilon_{d}$ \\
\hline${ }^{131}$ I sim & 53.160 & 57.990 & 88.510 & 0.70319 \\
${ }^{131}$ I sim & 276.390 & 40.801 & 296.150 & 0.14786 \\
${ }^{131}$ I sim & 303.000 & 86.024 & 758.550 & 0.12170 \\
${ }^{131}$ I sim & 356.010 & 184.860 & 2566.500 & 0.017730 \\
${ }^{131}$ I sim & 661.500 & 19.830 & 385.100 & 0.05527 \\
${ }^{60}$ Co & 1173.000 & 108.028 & 3573.290 & 0.03244 \\
${ }^{60}$ Co & 1332.000 & 97.690 & 3579.020 & 0.02929 \\
\hline
\end{tabular}

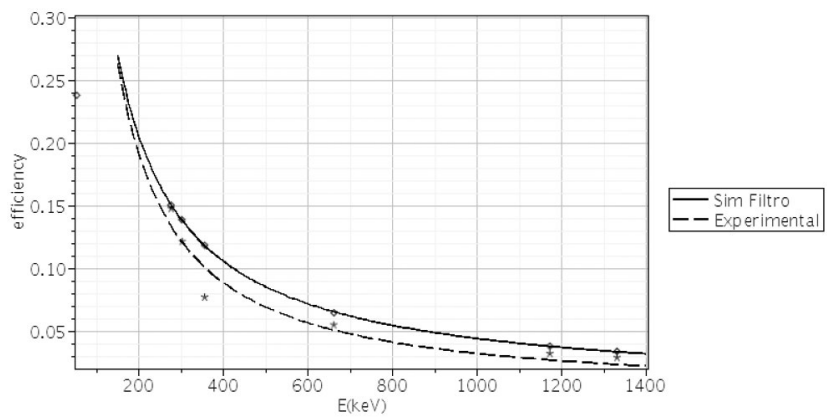

Fig. 3. Curve of efficiency.

be applied either for the calibration source or the impregnated filter. Then the correction factor $c f$ is:

$$
c f=\frac{g f_{\text {calibrationsoruce }}}{g f_{\text {filter }}}
$$

where $g f$ is the geometric factor. With this method, the cor- 190 rection factor is 0.93680 . By using seven MCNP5 code sim- 191 ulations, one for each energy, the mean correction factor is 192 0.93184. Efficiency $\varepsilon_{d}$ for energy $E_{i}$ is determined as:

$$
\varepsilon_{d}=\frac{1}{c f} \cdot \frac{N_{i}}{S_{i}}
$$

where $N_{i}$ represents the net count rate of the full energy peak 194 corresponding to the source gamma rays with energy $E_{i}$ and $S_{i} \quad 195$ is the intensity of photons with energy $E_{i}$. Intensity is deter- 196 mined for the two components of the simulated ${ }^{131} \mathrm{I}:{ }^{137} \mathrm{Cs}$ and 197 ${ }^{133} \mathrm{Ba}$, which are treated as two separate sources.

$$
S_{i}=\nu_{i} \cdot A_{i}(0) e^{-T_{t} \cdot \lambda_{i}} ; i={ }^{137} C s,{ }^{133} \mathrm{Ba}
$$

where $\nu_{i}$ is the emission probability of photons with energy $E_{i}, \quad 200$ $A_{i}(0)$ is the activity on the calibration date of the source, $T_{t}$ is 201 the time between the calibration date of the source and the day 202 of the experiment and $\lambda_{i}$ is the disintegration constant. With 203 equations (6) and (7) we find the values of $\varepsilon_{d}$ on Table II. A 204 second efficiency curve, obtained from MCNP5, is compared 205 with that obtained from experimental values, Fig. 3. As can 206 be seen, the two curves are very close, with the exception of 207 experimental efficiency for $380 \mathrm{keV}$. By fitting the experimen- 208 tal points without considering the $380 \mathrm{keV}$ experimental value, 209 efficiency is:

$$
\varepsilon_{d}= \begin{cases}0.43792 & 100 \mathrm{keV} \leq E \leq 200 \mathrm{keV} \\ 60.71703 \cdot E^{-1.07096} & E>200 \mathrm{keV}\end{cases}
$$




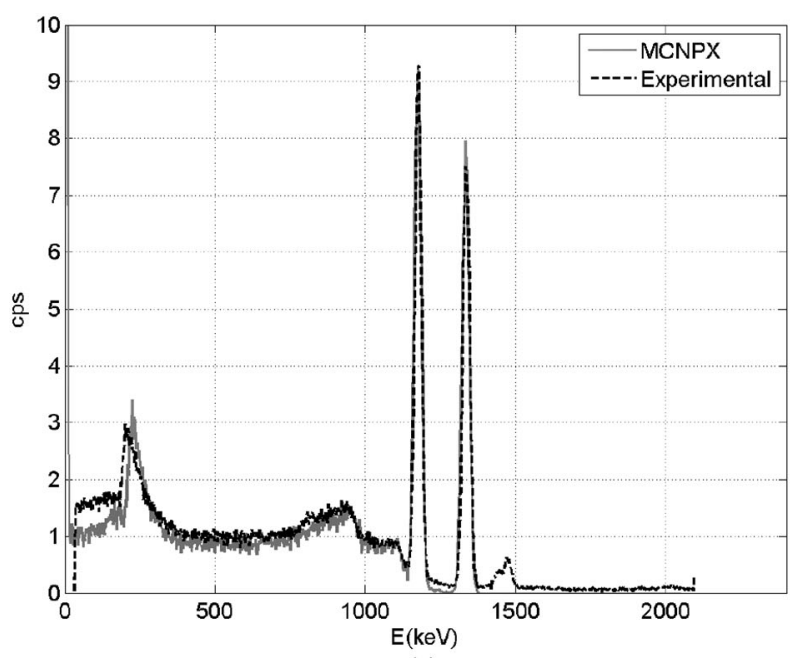

(a)

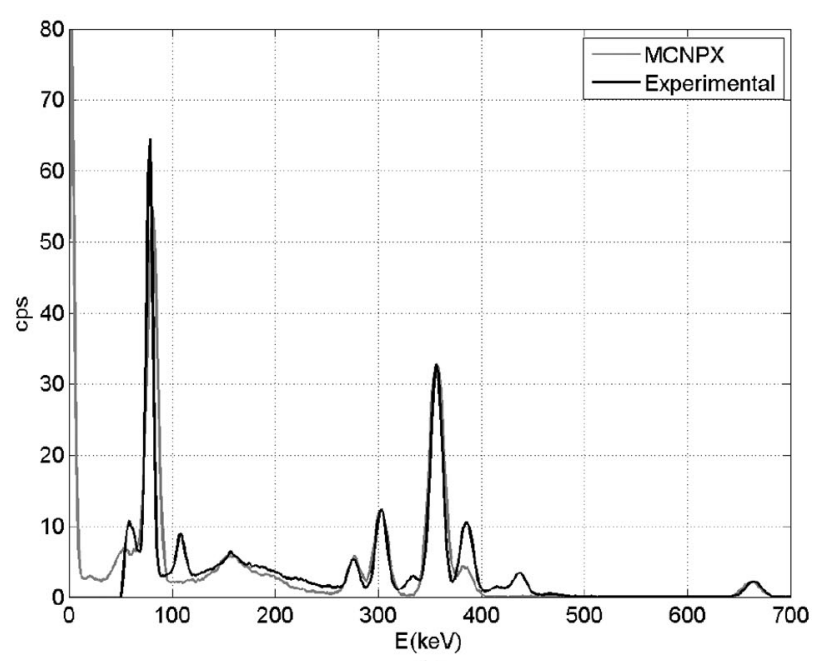

(b)

F4:1 Fig. 4. Comparison between simulated and experimental spectra. Experimental F4:2 setup: $\operatorname{LaBr}_{3} 2^{\prime \prime} \times 2^{\prime \prime}$ scintillator and the DigiBASE compact instrumentation F4:3 from ORTEC. The source is inside the volume of detection equipment for conF4:4 tinuous measurement and identification of gamma radioactivity in aerosols with F4:5 paper filter. (a) Co-60 (b) Simulated I-131.
Since Monte Carlo methods were used to complement the experimental values to obtain the efficiency curve, the equipment simulation model must be benchmarked. In fact, without the geometry correction, Fig. 3 itself could be a validation of the Monte Carlo simulations. It is interesting to analyze and compare the experimental and Monte Carlo simulated spectra of the equipment with the calibration source instead of the paper filter. As the sources were very close to the front window of the detector, some true coincidence summing peaks appeared on the spectrum. These cannot be reproduced with a single MCNP5 simulation, but as we want to compare the procedure used to obtain the efficiency curve and these sum peaks are not required for the efficiency calculations, we will not simulate them. Fig. 4 compares simulated and experimental ${ }^{60} \mathrm{Co}$ and simulated source of ${ }^{131} \mathrm{I}$ spectra. The simulation reproduces perfectly the processes that not depend on the electronic instrumentation modules. As can be seen, backscattering peaks, Compton continuum, Compton valley and two
TABLE III

COMPARISON OF NET COUNTS OF PEAKS

\begin{tabular}{c|cc}
\multicolumn{3}{c}{ Net Counts ${ }^{60}$ Co (cps) } \\
\hline $\mathrm{E}(\mathrm{keV})$ & Experim. & MCNP \\
\hline 1173 & 107.95 & 122.13 \\
1332 & 97.62 & 112.34 \\
\hline
\end{tabular}

\begin{tabular}{c|cc|cc}
\multicolumn{3}{c}{ Net Conts ${ }^{131}$ I (cps) } & Gross counts ${ }^{131}$ I (cps) \\
\hline E $(\mathrm{keV})$ & Experim. & MCNPX & Experim. & MCNP \\
\hline 60 & 24.11 & 8.60 & 57.99 & 65.19 \\
80 & 189.18 & 303.36 & 260.91 & 380.45 \\
276 & 21.02 & 17.61 & 40.80 & 44.48 \\
303 & 63.31 & 73.27 & 86.02 & 104.65 \\
356 & 184.86 & 249.07 & 231.13 & 291.88 \\
661.5 & 19.83 & 22.51 & 22.32 & 22.79 \\
\hline
\end{tabular}

full energy peaks appear. The differences between both spectra 229 are due to the fact that background radiation is not simulated. 230 Intrinsic radiation from the $\mathrm{LaBr}_{3}(\mathrm{Ce})$ scintillator, i.e. ${ }^{138} \mathrm{La} 231$ and ${ }^{138} \mathrm{La}$ plus X-rays peaks at $1468 \mathrm{keV}$, appears in the experi- 232 mental spectrum. This component was not simulated, but is not 233 relevant for efficiency calibration. Moreover, at low energies 234 the simulated spectrum has fewer counts than the experimental 235 one. This is because the Monte Carlo model does not simulate 236 the background radiation components of cosmic rays or earth's 237 NORMs, resulting in fewer X-rays on the lead shielding (peak 238 near $80 \mathrm{keV}$ in the spectrum). In our model, only X-rays from 239 absorption of the calibration source radiation are generated. 240 Again, this is not important for efficiency calculation.

Since the simulated ${ }^{131}$ I has many peaks at low energies, the 242 effect of sum peaks is more noticeable, at least in our energy 243 range (0-2048 keV). Monte Carlo does not generate sum peaks, 244 as can be seen in Fig. 4. For full energy peaks with little or no 245 influence of sum peaks, simulation results are good. Table III 246 compares the net areas of full energy peaks of simulated and 247 experimental spectra. Peaks influenced by a sum peak are not 248 used in efficiency calibration.

\section{Determination of The ACtivity Concentration 250}

After identification of gamma emitters in the spectrum, the 251 spectrometric analysis system determines their specific activity 252 in the air $\tilde{A}_{a}$, expressed in $\mathrm{Bq} / \mathrm{m}^{3}$, according to the net area of 253 the most efficient emitter of the isotope. However, the obtained 254 spectrum corresponds to the number of counts caused by the 255 radionuclide concentration on the filter, which is different from 256 the radionuclide concentration in the air. Because the activity on 257 the filter $A_{f}$ is proportional to the number of captured atoms, 258 a balance of activity can be performed in the same way as for 259 concentration. The radionuclide concentration of an analysed 260 emitter on the filter at a certain time depends on three factors: 261 1) the number of captured atoms of this emitter; 2) decays of 262 the parent nuclei of this emitter, and 3) decays of this emitter. 263

Activity on the filter $A_{f}$ is proportional to activity in the air 264 $\tilde{A}_{a}$, air flow $\mathrm{Q}$, and retention efficiency of the filter $\varepsilon_{f}$ [4], [5]. 265 Nevertheless, as activity on the filter implies a balance of matter 266 on the filter, concentration of each radionuclide depends on its 267 
position in the decay series. In the case of aerosol equipment, the radionuclides are belonging to the ${ }^{238} \mathrm{U}_{-}{ }^{222} \mathrm{Rn}$ series, the ${ }^{232} \mathrm{Th}-{ }^{220} \mathrm{Rn}$ (chiefly ${ }^{212} \mathrm{~Pb},{ }^{212} \mathrm{Bi}$ and ${ }^{208} \mathrm{Tl}$ ) series or to none of the series. A slightly different statement is required for each case.

\section{A. Radionuclides not Belonging to a Series}

Most artificial emitters fall in this category. The balance of matter in this case is simply:

$$
\frac{d A_{f}}{d t}=Q \varepsilon_{f} \tilde{A}_{a}(0)-\lambda_{i} A_{f}
$$

Equation (9) can be solved by integration and as result the filter activity of the emitter analysed is:

$$
A_{f}(t)=\frac{Q \cdot \varepsilon_{f} \cdot \tilde{A}_{a}}{\lambda} \int_{0}^{T} 1-e^{-\lambda t} d t
$$

Then, from Equation (10), the specific activity $\tilde{A}_{a}$ in the air for emitter $i$ (expressed $\mathrm{Bq} / \mathrm{m}^{3}$ ) is:

$$
\tilde{A}_{a}=\frac{\lambda_{i} N_{i} T}{Q \varepsilon_{f} \varepsilon_{d} \nu_{i} \int_{0}^{T}\left(1-e^{-\lambda_{i} t}\right) d t}
$$

Where $\lambda_{i}$ is the decay constant for radionuclide $i, N_{i}$ the net area (counts per second) of the full energy peak of the most probable gamma of radionuclide $i, T$ the detection time (live time fo the Multiple Channel Analyzer), $Q$ the average airflow, $\varepsilon_{f}$ the filter efficiency, $\varepsilon_{d}$ the detection efficiency for the most probable gamma of radionuclide $i$, and $\nu_{i}$ the emission probability of the most probable gamma of radionuclide $i$.

\section{B. ${ }^{238} U-{ }^{222} R n$ Series}

The gamma emitters in the air of interest belonging to the decay series of ${ }^{238} \mathrm{U}$ are the descendents of ${ }^{222} \mathrm{Rn}$ :

$$
{ }^{222} \mathrm{Rn} \stackrel{\alpha}{\longrightarrow}{ }^{218} \mathrm{Po}(1) \stackrel{\alpha}{\longrightarrow}{ }^{214} \mathrm{~Pb}(2) \stackrel{\beta}{\longrightarrow}{ }^{214} \mathrm{Bi}(3)
$$

Numbers in parenthesis in the chain (12) represent the nomenclature used for the radionuclides in the following equations. These radionuclides are present on all countings because they come from the earth and surrounding buildings. Among them we can find some gamma emitters of certain importance, mainly ${ }^{214} \mathrm{~Pb}$ and ${ }^{214} \mathrm{Bi}$. The equations of balance of matter for chain (12) are:

$$
\begin{aligned}
\frac{d A_{f 1}}{d t} & =\tilde{A}_{a 1}(0) Q \varepsilon_{f}-\lambda_{1} A_{f 1} \\
\frac{A_{f 2}}{d t} & =\lambda_{1} A_{f 1}+\tilde{A}_{a 2}(0) Q \varepsilon_{f}-\lambda_{2} A_{f 2} \\
\frac{d A_{f 3}}{d t} & =\lambda_{2} A_{f 2}+\widetilde{A}_{a 3}(0) Q \varepsilon_{d}-\lambda_{3} A_{f 3}
\end{aligned}
$$

${ }^{218}$ Po reaches its equilibrium at $95 \%$ in 13 minutes. By comparing the partial time of detection of $1 \mathrm{~h}$ and the total time of detection of $24 \mathrm{~h}$, the hypothesis that ${ }^{218} \mathrm{Po}$ and ${ }^{214} \mathrm{~Pb}$ are in equilibrium in the air can be supported.

$$
\tilde{A}_{a 1}(0)=\tilde{A}_{a 2}(0)
$$

By considering the equilibrium condition Eq. (14) and devel- 301 oping the balance equations Eq. (13), the specific activities of 302 ${ }^{214} \mathrm{~Pb}$ and ${ }^{214} \mathrm{Bi}$ can be determined by:

$$
\tilde{A}_{a 2}(0)=\frac{1}{2} \frac{N_{2} T \lambda_{2}}{Q \nu_{2} \varepsilon_{f} \varepsilon_{d_{2}} \int_{0}^{T}\left(1-e^{-\lambda_{2} t}\right) d t}
$$

The equation of balance of matter for chain 12 is (for simplicity 304 we omit the explicit time dependences here):

$$
\begin{aligned}
\tilde{A}_{a 3}(0)= & \frac{\lambda_{3} N_{3} T}{Q \nu_{3} \varepsilon_{f} \varepsilon_{d_{3}} \int_{0}^{T}\left(1-e^{-\lambda_{3} t}\right) d t} \\
& -\frac{2 \tilde{A}_{a 2}(0)}{\int_{0}^{T}\left(1-e^{-\lambda_{3} t}\right) d t}\left[\int_{0}^{T}\left(1-e^{-\lambda_{3} t}\right) d t\right. \\
& \left.+\frac{\lambda_{3}}{\lambda_{2}-\lambda_{3}} \int_{0}^{T}\left(e^{-\lambda_{2} t}-e^{-\lambda_{3} t}\right) d t\right]
\end{aligned}
$$

Emission probability $\nu_{i}$, the net area of the full energy peak 306 $N_{i}$ and detection efficiency $\varepsilon_{i}$ correspond to the most probable 307 gamma of the analised radionuclide.

\section{C. ${ }^{232}$ Th- ${ }^{220}$ Rn Series}

As in the previous case, only the nuclides at the end of the 310 chain are of interest in this series, i.e. from ${ }^{220} \mathrm{Rn}$ :

$$
{ }^{220} \mathrm{Rn} \stackrel{\alpha}{\longrightarrow}{ }^{216} \mathrm{Po}(1) \stackrel{\beta}{\longrightarrow}{ }^{212} \mathrm{~Pb}(2) \stackrel{\beta}{\longrightarrow}{ }^{212} \mathrm{Bi}(3) \stackrel{\beta}{34 \%}{ }^{208} \mathrm{Tl}(4)
$$

These radionuclides are always present in air aspiration, like 312 in the previous series. Among them, ${ }^{212} \mathrm{~Pb},{ }^{212} \mathrm{Bi}$ and ${ }^{208} \mathrm{Tl} 313$ are detected by the equipment. ${ }^{212} \mathrm{~Pb}$ bifurcates to ${ }^{208} \mathrm{Tl}$ with 314 $35.94 \%$ and to ${ }^{212}$ Po with $64.06 \%$, but ${ }^{212}$ Po is not an impor- 315 tant $\gamma$ emitter. However, in the location areas of our monitoring 316 stations there are fewer of those than of the ${ }^{238} \mathrm{U}_{-}{ }^{222} \mathrm{Rn}$ series, 317 and in typical spectra generated by the equipment only the pres- 318 ence of ${ }^{212} \mathrm{~Pb}$ is detected. The balance of matter is similar to 319 that of the previous series Eq. 13. The half-life of ${ }^{216} \mathrm{Po}$ is 320 $0.15 \mathrm{~s}$. Hence, it can be assumed that at the end of detection 321 equilibrium exists between ${ }^{216} \mathrm{Po}$ and ${ }^{212} \mathrm{Bi}$.

\section{AnAlysis of ${ }^{131} \mathrm{I}$}

\section{A. Identification and Minimum Detectable Activity (MDA)}

Full energy peaks of ${ }^{131}$ I gamma emitters are very close 325 to some full energy peaks of ${ }^{212} \mathrm{~Pb},{ }^{214} \mathrm{~Pb}$ and ${ }^{214} \mathrm{Bi}$. These 326 natural emitters belong to the ${ }^{222} \mathrm{Rn}$ radon and ${ }^{220} \mathrm{Rn}$ thoron 327 series, and are always present in the spectrum. Overlapping 328 of iodine gamma lines with other emmiters occurs between 329 the $284.2 \mathrm{keV}, 364.4 \mathrm{keV}$ and $636.97 \mathrm{keV}$ peaks of ${ }^{131} \mathrm{I} .330$ The $722.89 \mathrm{keV}$ peak does not overlap with those of natu- 331 ral emitters, but it has very low emission probability. Like the 332 $80.18 \mathrm{keV}$ of ${ }^{131} \mathrm{I}$, that does not overlap with other peaks, but is 333 outside the linear operating range of the scintillator. Therefore, 334 to identify ${ }^{131}$ I we can only use full energy peaks overlapped 335 with natural emitter peaks, which are always present in the 336 


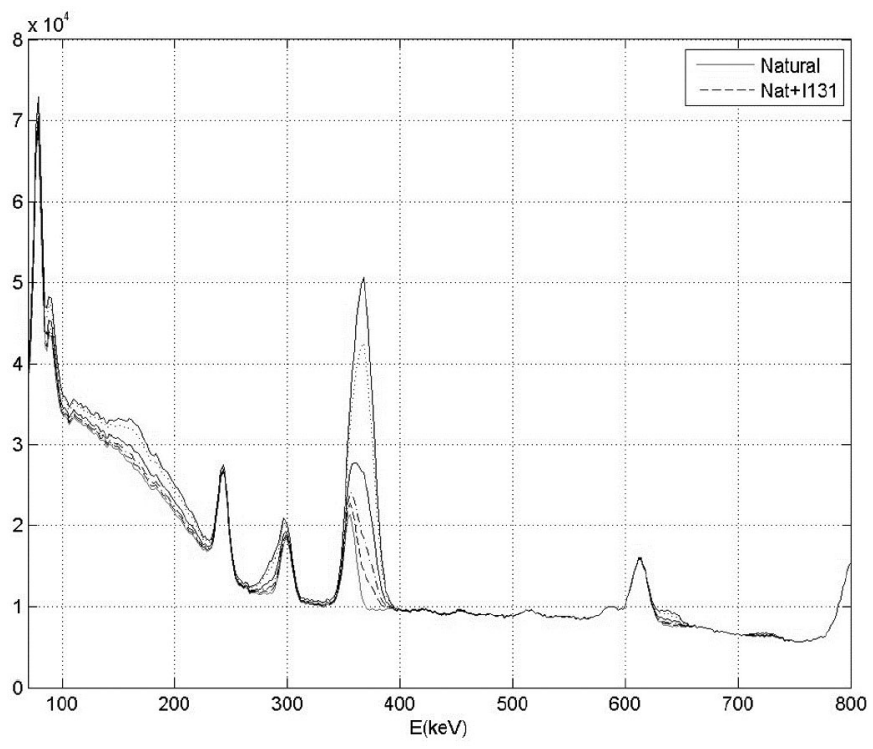

F5:1 Fig. 5. Spectra of ${ }^{131}$ I. Obtained by a combination of experimental backF5:2 ground and simulations with the filter impregnated with ${ }^{131} \mathrm{I}$. The different F5:3 lines represents the spectra for different concentrations of ${ }^{131} \mathrm{I}$. spectrum. As a consequence, the minimum detectable activity of ${ }^{131} \mathrm{I}$ is greater than for other emitters.

Identification of ${ }^{131}$ I was accomplished using several equipment simulations where the filter was impregnated with ${ }^{131} \mathrm{I}$. These simulated spectra was combined with an experimental background spectrum. The resultant spectra is shown in Fig. 5 When the $364.4 \mathrm{keV}$ peak is identified as ${ }^{131} \mathrm{I}$ instead of ${ }^{214} \mathrm{~Pb}$ in the combined spectrum analised by pGamma, the activity of ${ }^{131}$ I ranges between $0.4 \mathrm{~Bq} / \mathrm{m}^{3}$ and $0.8 \mathrm{~Bq} / \mathrm{m}^{3}$. The latter is its Minimum Detectable Activity (MDA). For comparison, ${ }^{60} \mathrm{Co}$ MDA is $0.02402 \mathrm{~Bq} / \mathrm{m}^{3}$ and ${ }^{137} \mathrm{Cs}$ MDA is $0.01662 \mathrm{~Bq} / \mathrm{m}^{3}$ (the air flow for the experimental background spectrum was $\left.8.870 \mathrm{~m}^{3} / \mathrm{h}\right)$.

\section{B. Determination of Specific Activity}

The activity concentration of ${ }^{131}$ I can be determined using the filter's retention efficiency, which has already been studied by several authors ([4], [5]). It depends on the iodine species, particle size and air flow. The equipment for continuous measurement and identification of gamma radioactivity in aerosols for which this version of the pGamma code has been developed uses a GF 10 from Hahnemühle fiberglass paper filter. The fiberglass paper filter can only retain iodine particles. Their average size can be found in a number of works [6], [7]. Their diameter typically ranges between $0.2 \mu \mathrm{m}$ and $0.5 \mu \mathrm{m}$. The air flow of the equipment in normal operation is $110 \mathrm{~m}^{3} / \mathrm{h}$. In these conditions, the efficiency of the GF 10 filter for iodide can be considered as:

$$
\varepsilon_{f}=\left\{\begin{array}{l}
99-0 \%(\text { for particles }) \\
0 \%(\text { for all the other cases })
\end{array}\right.
$$

However, the estimation of filter efficiency is not enough to determine the activity concentration of ${ }^{131} \mathrm{I}$. Iodine can appear as a particle or gas in the form of elemental $\mathrm{I}_{\text {or }} \mathrm{I}^{2}$, organic 366 (chiefly methyl iodide $\mathrm{CH}^{3} \mathrm{I}$ ) or inorganic (hypoiodous HOI). 367 The GF 10 filter does not capture all iodine species (actu- 368 ally, no filter does); it only retains particles. The only way 369 to determine total activity concentration in the air is to know 370 the concentration of iodine particles at the surveillance sta- 371 tion, but this is impossible because of the special behavior of 372 iodine transport in the atmosphere. The composition of iodine 373 can be measured by gas chromatography [8], but this method 374 is outside the equipment's concept. Several authors have made 375 estimates from information collected during the Chernobyl or 376 Fukushima accidents. For example, in [9] it was estimated that 377 $50 \%$ of iodine is particles and the rest is gaseous. In his book 378 [10], A. C. Chamberlain reports some particle-gas rate val- 379 ues, but they differ significantly from each other. Finally, the 380 assumption in RASCAL 4.3 code [11], i.e. $33 \%$ of iodine par- 381 ticles, was considered for this work. We must bear in mind that 382 the final purpose of the equipment is not to perform accurate 383 measurements of air component concentration, but to provide 384 information about gamma emitters in the air, such as the above 385 estimates.

\section{Action LeVEls}

Three action levels are provisionally considered ${ }^{2}$ :

1) Investigation level.

2) Alert level, according to the concentration limit value in 390 the air for public members (concentration giving by a 391 dose $1 \mathrm{mSv} /$ year).

3) Alarm level, according to twice the concentration limit 393 value for the public.

The investigation level is initiated when:

1) The activity detected exceeds activity concentration 396 thresholds for critical anthropogenic or natural isotopes 397 stored in a library. For the former, the threshold is 398 based on the recommendation of the 18 December 2003399 Commission, (2004/2/EURATOM) DO L2/36 (6.1.2004). 400 For NORM radionuclides, the threshold is based on sta- 401 tion measurement values (e.g. $2 \cdot 10^{-2} \mathrm{~Bq} / \mathrm{m}^{3}$ for ${ }^{131} \mathrm{I} 402$ and $3 \cdot 10^{-2} \mathrm{~Bq} / \mathrm{m}^{3}$ for $\left.{ }^{137} \mathrm{Cs}\right)$.

2) The analysis report contains one or more unidentified 404 peaks.

3) The variation of the total number of counts on the detec- 406 tor during consecutive identical periods of time, defined 407 as Relative Variation in the Number of Counts (RVC), 408 exceeds an empirical value. This can be expressed as:

$$
\frac{d C}{C}=\frac{C\left(t_{2}\right)-C\left(t_{1}\right)}{C\left(t_{1}\right)}
$$

Where $C\left(t_{1}\right)$ and $C\left(t_{2}\right)$ are the number of counts on two 411 consecutive identical periods of time. After a year of operation 412 we propose a statistic analysis of the results and a revision of 413 the investigation levels.

${ }^{2}$ Provided by the Spanish "Consejo de Seguridad Nuclear” (Nuclear Security Council) 


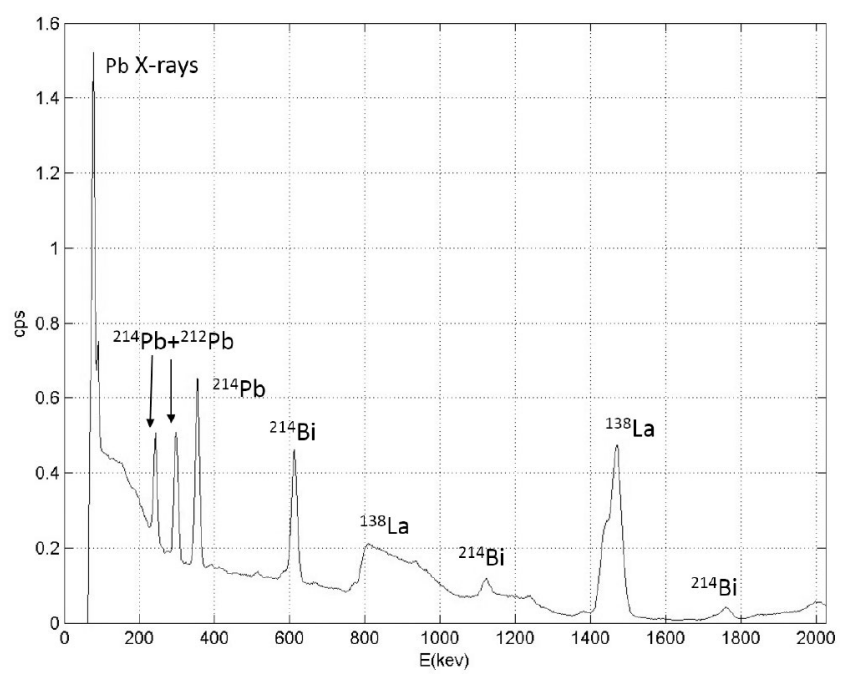

F6:1
Fig. 6. Spectrum analised, obtained with the equipment for continuous measurement and identification of gamma radioactivity in aerosols with paper filter $\left(2^{\prime \prime} \times 2^{\prime \prime} \mathrm{LaBr}_{3}\right.$ scintillator with digiBASE form ORTEC).

TABLE IV

Detectable NORM Gamma EmitTers From Aersols [12]

\begin{tabular}{|c|c|c|}
\hline Emitter & Series & Gammas emitted (keV) \\
\hline${ }^{214} \mathrm{~Pb}$ & ${ }^{238} \mathrm{U}_{-}{ }^{222} \mathrm{Rn}$ & $\begin{array}{c}242(7.2 \%), 295.22(18.5 \%), 351.93 \\
(35.6 \%)\end{array}$ \\
\hline${ }^{214} \mathrm{Bi}$ & ${ }^{238} \mathrm{U}^{222} \mathrm{Rn}$ & $\begin{array}{c}609.31(45.49 \%), 1120.29(14.09 \%), \\
1764.49(15.28 \%), 1847.42(2 \%) 2204.21 \\
(4.9 \%)\end{array}$ \\
\hline${ }^{212} \mathrm{~Pb}$ & ${ }^{232} \mathrm{Th}^{220} \mathrm{Rn}$ & $238.63(43.6 \%), 300.09(3.18 \%)$ \\
\hline${ }^{212} \mathrm{Bi}$ & ${ }^{232} \mathrm{Th}^{220} \mathrm{Rn}$ & $727.33(6.74 \%), 1620.74(1.51 \%)$ \\
\hline${ }^{208} \mathrm{Tl}$ & ${ }^{232} \mathrm{Th}-{ }^{220} \mathrm{Rn}$ & $\begin{array}{c}510.7(6.29 \%), 583.19(30.6 \%), 2614.51 \\
(35.85 \%)\end{array}$ \\
\hline
\end{tabular}

\section{Analysis of a Spectrum by PGamma}

This section presents a pGamma analysis example of a typical $24 \mathrm{~h}$ spectrum obtained at Ascó station on 10 January 2015. The average air flow was $8.35 \mathrm{~Bq} / \mathrm{m}^{3}$, there was no rainfall and the temperature ranged between $7^{\circ} \mathrm{C}$ and $15^{\circ} \mathrm{C}$. The spectrum is shown in Fig. 6. Note that the peaks caused by NORM, i.e. detectable gamma emitters of the ${ }^{238} \mathrm{U}$ series and ${ }^{212} \mathrm{~Pb}$ of the ${ }^{232} \mathrm{Th}$ series, appear combined with the intrinsic spectrum of the $\mathrm{LaBr}_{3}$ detector. No anthropogenic emitters are observed in the air.

Considering the spectrum in Fig. 6, the components are: 1) Aerosols (mainly NORM) retained on the filter; 2) Cosmic particles and their interaction with elements on the detection zone and 3) Intrinsic spectrum of the detector. Table IV illustrates the detectable gamma peaks of the ${ }^{238} \mathrm{U}$ and ${ }^{232} \mathrm{Th}$ series. Fig. 7 shows the background spectrum (without air suction or aerosol retention) generated by the equipment. The cosmic component is only important at low energies. The level of intrinsic radiation from the detector is very significant in the range of interest, even higher than for the component resulting from aerosols retained on the filter. The radiation generated in the $\mathrm{LaBr}_{3}$ crystal is mainly due to ${ }^{138} \mathrm{La}$ (Fig. 8). The most important peaks of the intrinsic spectrum of the $\mathrm{LaBr}_{3}$

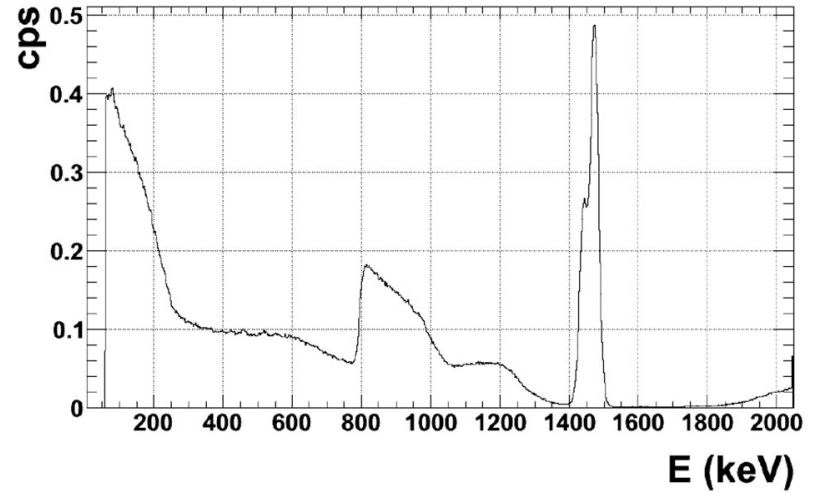

Fig. 7. Background spectrum of the equipment of the measurement of gamma F7:1 radiation on aerosols by paper filter.

F7:2

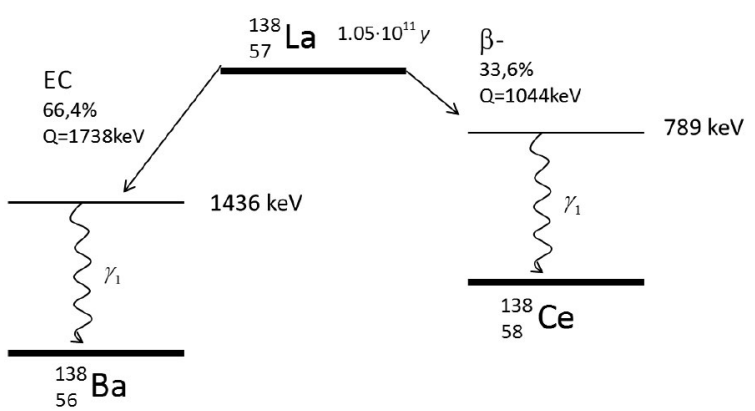

Fig. 8. Decay scheme for ${ }^{138} \mathrm{La}$ [13].

F8:1

scintillation detector are: 1 ) between $(0-300) \mathrm{keV} \beta$ continuous; 438 2) between (700-1100) $\mathrm{keV} \beta$ continuous plus gammas of 439 $789 \mathrm{keV}$; 3) between (1400-1500) keV gammas of $1436 \mathrm{keV} 440$ and a sum peak of gammas of $1436 \mathrm{keV}$ and X-rays of $32 \mathrm{keV} . \quad 441$

Fig. 9 shows the pGamma report of the analised spectrum. 442 The report has four parts: 1) overall parameters of the spec- 443 trum; 2) specific activity of identified isotopes (first column for 444 activity, second for error and third for the minimum detectable 445 activity); 3) identified peaks; and 4) unidentified peaks. $\quad 446$

Following the list of expected peaks (Table IV), the code 447 identified: 1) The most probable ${ }^{214} \mathrm{~Pb}$ peaks; 2) The most prob- 448 able ${ }^{214} \mathrm{Bi}$ peaks; 3) One ${ }^{212} \mathrm{~Pb}$ peak; and 4) The $789 \mathrm{keV}$ and 449 of $1436 \mathrm{keV} \gamma$ peaks and the combination of the $\gamma$ of $1436 \mathrm{keV} \quad 450$ with the X-ray of $32 \mathrm{keV}$ of the intrinsic spectrum of the $\mathrm{LaBr}_{3} \quad 451$ crystal. ${ }^{212} \mathrm{Bi}$ does not appear in the list of identified peaks 452 because its gamma rays have a very low emission probability 453 and its full energy peaks are not significant enough. ${ }^{208} \mathrm{Tl}$ has no 454 identified peaks. From ${ }^{208} \mathrm{Tl}$, the $510.7 \mathrm{keV}$ peak is very close 455 to the annihilation peak and is too small to be distinguished by 456 a scintillator, the same is true of the $583.19 \mathrm{keV}$ peak. This one 457 is important but very close to the $609.31 \mathrm{keV}$ peak of ${ }^{214} \mathrm{Bi}, \quad 458$ which is a very significant one, and therefore the overlapping 459 peak is assigned to ${ }^{214} \mathrm{Bi}$. The $2614.51 \mathrm{keV}$ peak is out of the 460 operating range of the equipment. It must be remembered that, 461 with the resolution of scintillators, the $242 \mathrm{keV}$ and $295.22 \mathrm{keV} \quad 462$ peaks of ${ }^{214} \mathrm{~Pb}$ coincide with the ${ }^{212} \mathrm{~Pb}$ peaks. Finally, the peak 463 6 at $514.1 \mathrm{keV}$ is the annihilation peak. 
[1]

11640368

10179770

[2]

pb212 SerieTh232Rn220 3.15e-001 3.56e-003 6.98e-0031

bi214 Serieu238Rn222 $1.42 e+001 \quad 8.05 e-002 \quad 2.88 e-001710 \quad 1$

$\begin{array}{llll}12 & 13 & 17 & 18\end{array}$

pb214 SerieU238Rn222 1.49e+001 7.23e-002 1.47e-001 23 [3]

pb212 $1121.1 \quad 241.7 \quad 241.8 \quad 4.4 \quad 115 \quad 133 \quad 14.4 \quad 135857.7$

SerieTh232Rn220

bi214 $7307.0 \quad 611.0 \quad 609.6 \quad 9.6 \quad 286 \quad 326 \quad 20.9 \quad 302812.7$ SerieU238Rn222

bi214 $10 \quad 467.6 \quad 932.4 \quad 936.5 \quad 5.4 \quad 464 \quad 479 \quad 18.4 \quad 5440.6$ SerieU238Rn222

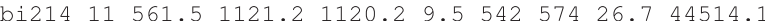

SerieU238Rn222

$\begin{array}{llllllllll}\text { bi214 } & 12 & 618.1 & 1235.2 & 1238.1 & 6.3 & 612 & 667 & 23.1 & 8134.9\end{array}$

SerieU238Rn222

bi214 $13 \quad 690.1 \quad 1380.9 \quad 1375.5 \quad 7.1 \quad 676 \quad 695 \quad 19.7 \quad 4868.6$

SerieU238Rn222

bi214 $17876.3 \quad 1759.3 \quad 1753.0 \quad 17.6 \quad 846 \quad 894 \quad 33.7 \quad 51719.2$ SerieU238Rn222

bi214 $18921.8 \quad 1852.1 \quad 1841.19 .9902927 \quad 30.14166 .6$ SerieU238Rn222

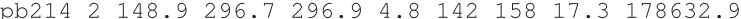
SerieU238Rn222

pb214 $3 \quad 177.6 \quad 353.5 \quad 353.4 \quad 5.5 \quad 168 \quad 186 \quad 14.1 \quad 304242.5$

SerieU238Rn222

anio $6 \quad 257.8 \quad 512.9 \quad 514.1 \quad 5.3 \quad 252 \quad 266 \quad 17.0 \quad 7653.3$ Pic

$\mathrm{d}^{\prime}$ aniquilació

$\begin{array}{lllllllllll}\text { la138 } & 9 & 405.2 & 807.1 & 818.3 & 19.8 & 391 & 438 & 52.7 & 172130.3\end{array}$

Intrinsec

la138 $14 \quad 733.3 \quad 1468.4 \quad 1468.6 \quad 7.8 \quad 723 \quad 780 \quad 21.9 \quad 229245.5$

Intrinsec

[4]
The pGamma code is an automatic spectrometric analysis system for environmental radiation monitoring equipment with spectrometric capability. The version presented in this paper was specifically designed for our equipment of continuous measurement and identification of gamma radioactivity in aerosols with paper filter. Nevertheless, the code is perfectly adaptable to other equipment of the environmental radiological surveillance network of the local Catalan Government. The code identifies gamma emitters in the energy spectrum and determines their specific activity. If an emitter is not identified or activity concentration of any identified emitter exceeds an empirical threshold, an alarm is generated.

\section{REFERENCES}

[1] A. Savitzky and M. Golay, "Smoothing and differentiation of data by sim- 479 plified least squares procedures," Anal. Chem., vol. 36, pp. 1627-1639, 480 1964.

[2] E. Browne and R. Firestone, Table of Radioactive Isotopes, S. Shirley, 482 Eds. New York, NY, USA: Wiley, 1986.

[3] S. Organizations, Multi-Agency Radiological Laboratory Analytical 484 Protocols Manual (MARLAP). Cap 15 Quantification of Radionuclides. 485 NUREG-1576 / EPA 402-B-04-001A / NTIS PB2004-105421, 486 United States Environmental Protection Agency et. al., Jul. 2004, 487 http://www.epa.gov/radiation/marlap/manual.html 488

[4] W. John and G. Reischl, "Measurements of the filtration efficiencies of 489 selected filter types," Atmospher. Environ., vol. 12, pp. 2015-2019, 1978. 490

[5] E. Kitto and D. Anderson, "Correspondence. the use of whatman-41 491 filters for particle collection," Atmospher. Environ., vol. 22, no. 11, 492 pp. 2629-2630, 1988. $\begin{array}{ll}\text { Y. Miyamoto, K. Yasuda, and M. Magara, "Size distribution of radioac- } & 494 \\ \text { tive particles collected at tokai, japan } 6 \text { days after the nuclear accident" } & 495\end{array}$ J. Environ. Radioact., vol. 132, pp. 1-7, 2014.

[7] E. Bondietti, J. Brantley, and C. Rangarajan, "Size distributions and 497 growth of natural and chernobyl-derived submicron aerosols in ten- 498 nessee," J. Environ. Radioact., vol. 6, pp. 99-120, 1988.

[8] M. Naritomi, Y. Yoshida, and S. Fukuda, "Method for improving the col- 500 lecting performance of iodine samplers under high relative humidity," J. 501 Nucl. Sci. Technol., vol. 10, no. 5, pp. 292-300, 1973.

[9] S. MacMullin, G. Giovanetti, M. Green, R. Henning, R. Holmes, 503 K. Vorren, and J. Wilkerson, "Measurement of airborne fission products 504 in Chapel Hill, NC, USA from the Fukushima Daiichi reactor accident," 505 J. Environ. Radioact., vol. 112, pp. 165-170, 2012.

[10] A. Chamberlain, Radioactive Aerosols, 1st Cambridge, U.K.: Cambridge 507 Univ. Press, 1991.

[11] J. Ramsdell Jr., "Rascal 4.3. dispersion and deposition models," Proc. 509 18th Annu. George Mason Univ. Conf. Atmospheric Transport and 510 Dispersion Modelling, 2014.

[12] G. Gilmore, Practical Gamma-Ray Spectrometry, Hoboken, NJ, USA: 512 Wiley, 2008, http://books.google.es/books?id=mNHvAAAAMAAJ 513

[13] Scintillation products, Tech. note, Brillance Scintillators Performance 514 Summary, Saint Gobain Crystals Tech. Rep., 2009. 


\title{
A New Code for Spectrometric Analysis for Environmental Radiological Surveillance on Monitors Focused on Gamma Radioactivity on Aerosols
}

\author{
Alfredo de Blas, Member, IEEE, Albert Riego, Roger Garcia, Carlos Tapia, Javier Dies, Juan Toral, Enric Batalla, \\ and Pedro Diaz
}

\begin{abstract}
This paper presents a new code for the analysis of gamma spectra generated by an equipment for continuous measurement of gamma radioactivity in aerosols with paper filter. It is called pGamma and has been developed by the Nuclear Engineering Research Group at the Technical University of Catalonia - Barcelona Tech and by Raditel Serveis i Subministraments Tecnològics, Ltd. The code has been developed to identify the gamma emitters and to determine their activity concentration. It generates alarms depending on the activity of the emitters and elaborates reports. Therefore it includes a library with NORM and artificial emitters of interest. The code is being adapted to the monitors of the Environmental Radiological Surveillance Network of the local Catalan Government in Spain (Generalitat de Catalunya) and is used at three stations of the Network.
\end{abstract}

Index Terms-Environmental radiation, gamma activity, gamma spectrometry, isotope identification.

\section{INTRODUCTION}

$\mathbf{T}$ HE use of monitors with spectrometric capability in environmental radiological surveillance networks provides additional information that complements the ambient dose equivalent $\mathrm{H}^{*}(10)$. Based on this premise, our group (Nuclear Engineering Research Group) at the Technical University of Catalonia - Barcelona Tech and Raditel Serveis i Subministraments Tecnològics, Ltd. have developed an equipment for continuous measurement and identification of gamma radioactivity in aerosols with paper filter. Gamma spectrum analysis allows the identification and determination of activity concentration of radiation sources. Excellent commercial software is available for this purpose (among others, GammaVision form ORTEC and Genie2000 from

Manuscript received May 27, 2015; revised October 12, 2015; accepted January 21, 2016.

A. de Blas, A. Riego, R. Garcia, C. Tapia, J. Dies, and P. Diaz are with the Nuclear Engineering Research Group, Department of Physics and Nuclear Engineering, Technical University of Catalonia, 08028 Barcelona, Spain (e-mail: alfredo.de.blas@upc.edu).

J. Toral is with Raditel Serveis, 43005 Tarragona, Spain (e-mail: raditelserveis@gmail.com).

E. Batalla is with the Radiological Activities Corrdination Service (SCAR) of the Generalitat de Catalunya, 08003 Barcelona, Spain (e-mail: ebatalla@gencat.cat).

Color versions of one or more of the figures in this paper are available online at http://ieeexplore.iee.org.

Digital Object Identifier 10.1109/TNS.2016.2521388
CANBERRA). Nevertheless, it is generic software not intended for automatic analysis since each individual analysis must be conducted by a specialised technician. For this reason, our research group has developed a spectrometric analysis code specifically designed for the above equipment. This code is being used at stations with aerosol monitors on the Environmental Radiological Surveillance Network of the Generalitat de Catalunya (local Catalan Government), Spain ${ }^{1}$ : Three monitors are currently fully operative: two in the surveillance station of the Ascó and Vandellòs Nuclear Power Plants (both in the province of Tarragona, Spain), and one in the Engineering School of Barcelona, Spain. Two new monitors will shortly be deployed in Roses (province of Girona) and in Puigcerdà (province of Barcelona). The code has been adapted for the analysis of gamma spectra generated by other monitors with spectrometric capability of the Network, i.e. river and direct air monitors. We are starting the tuning of these versions of the code on the monitors for river and direct air.

The code, called pGamma, discriminates spectrum information, identifies emitters appearing on the spectrum, determines activity concentration in $\mathrm{Bq} / \mathrm{m}^{3}$ and generates alarms according to its calculated values. It has a normal operation mode and special operation mode for spectra obtained during energy calibration of the equipment. Additionally, another mode called investigation, is set when the variation in the total number of counts exceeds a certain level, or when a full energy peak is not identified.

The code input is an ASCII text file with the number of counts per channel of the spectrum and a header with information about measurement conditions: date and time of counting initiation and termination, live time, air flow, operation mode, the parameters of the energy calibration curve, etc. Fig. 1 is a general operation diagram of pGamma in normal operation mode.

The paper is organized as follows: Section II describes the treatment of the peaks in the spectrum. In Section III, efficiency calibration is presented. The determination procedure of activity concentration is shown in Section IV. Section V describes the identification of ${ }^{131}$ I. In Section VI, the action levels are

\footnotetext{
${ }^{1}$ This network is integrated in the Spanish Nuclear Security Council network.
} 


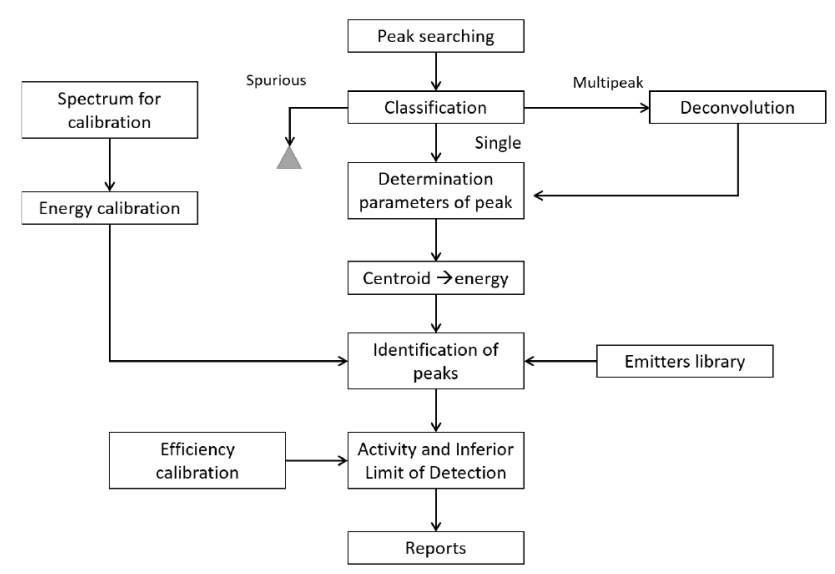

F1:1 Fig. 1. General diagram of pGamma.

presented. An Ascó station spectrum is analised in Section VII. Finally, conclusions are drawn in Section VIII.

\section{Peak Treatment}

The first step in the analysis of the spectrum is the treatment of the peaks: the searching of possible peaks on the spectrum and its identification.

\section{A. Peak Search}

Peak search and analysis is performed after the input spectrum is smoothed using the Savitzky-Golay method [1]. The smoothing algorithm allows the first, second and third derivatives of the spectrum to be obtained. The first derivative is used to determine the local maximums, which are subjected to a statistical test to discriminate real centrer of peaks (centroids) from spurious transitions. The nearest relative maximums of the first derivative at both sides of the centroid, indicate the channel of the peak boundaries. Using the second and the third derivate, single peaks are discriminated from multiplets. With the centroid and the boundaries of the peaks, the net area and the background are determined. The last step is the fitting of each peaks to a Gaussian curve. It allows the determination of the full width at half maximum (FWHM) and perform the chi-square test for further discrimination. With this information, pGamma generates a first list of possible peaks with their characteristics. The calculated parameters are centroid, lower and upper boundaries of the possible peak, full width at half maximum, gross area and net area.

\section{B. Peak Identification}

1) Energy Calibration: The use of energy calibration makes it possible to state the centroid, FWHM and limits of peaks in energy units instead of number of channels. The relationship between energy and adopted number of channel is:

$$
E=a+b C+c C^{2}
$$

Where $C$ is the channel and $a, b$ and $c$ are the parameters of the calibration curve. Energy calibration must be performed prior to installation of equipment in a station.
2) Peak Identification: Peaks can be identified using the 111 library of gamma emitters of interest included in the code. 112 This library has been created by us using information from [2]. 113 For aerosol equipment, these emitters are the NORM radionu- 114 clides $\left({ }^{238} \mathrm{U}_{-}{ }^{222} \mathrm{Rn}\right.$ series, ${ }^{232} \mathrm{Th}-{ }^{220} \mathrm{Rn}$ series, ${ }^{40} \mathrm{~K}$ and $\left.{ }^{7} \mathrm{Be}\right) \quad 115$ and artificial emitters from nuclear power plant discharges 116 (e.g. radio-iodines, ${ }^{137} \mathrm{Cs},{ }^{134} \mathrm{Cs}$ and ${ }^{132} \mathrm{Te}$ ) or industrial appli- 117 cations. Information about emitters includes energy and the 118 emission probability of emitted gamma rays, empirical thresh- 119 olds for NORM emitters to decide if pGamma must switch to 120 investigation mode and derived concentration limits in the air. 121

The centroid energy of each peak is compared with the 122 energy of gamma emitters. For similar values, the emitters are 123 considered candidates for that peak and a list of candidates 124 is generated. To identify a set of peaks with a radionuclide 125 with multiple gamma emissions, the ratio between intensity 126 of detected gammas and total intensity of the gammas of the 127 emitter in the library is used. The relationship between the 128 members of ${ }^{238} \mathrm{U}_{-}{ }^{222} \mathrm{Rn}$ series and ${ }^{232} \mathrm{Th}^{2}{ }^{220} \mathrm{Rn}$ series is con- 129 sidered too. pGamma cannot determine activity concentration 130 of unidentified peaks.

\section{Detection EFFiciency CALibRation}

In order to determine activity concentration, the code needs 133 information about the detection efficiency. Since the factors 134 integrating the detection efficiency are very difficult to deter- 135 mine due to a complex geometry and a wide range of possible 136 energies, efficiency calibration must be performed. First, the 137 same geometry of the paper filter (source), detector and detec- 138 tion volume of the equipment during normal operation must 139 be reproduced. This implies preparing a calibration source 140 by shaping it into a disc with the same diameter of aerosols 141 retained on the filter, and the same self-absorption (negligi- 142 ble) and gamma emitters of several energies in the range from 143 $100 \mathrm{keV}$ to $2000 \mathrm{keV}$. In consequence, the analytical determi- 144 nation of efficiency is cumbersome. The solution consists in 145 using a calibration source with similar characteristics to the 146 source to be measured and determining efficiency from experi- 147 mental values. To ensure unbiased calibration, the calibration 148 source should be identical to the radioactive samples in all 149 aspects affecting detection [3]. If no calibration source is avail- 150 able or more points are required for adjusting the efficiency 151 curve, Monte Carlo n-Particle (MCNP5, version 2.6.0) provide 152 a further possibility for calculating the detector efficiency. $\quad 153$

We used simulated ${ }^{131} \mathrm{I}$ and commercial ${ }^{60} \mathrm{Co}$ sources 154 (Table I) with similar geometry and materials to those of the 155 impregnated filter of the monitor. The simulated ${ }^{131}$ I source 156 is composed of two radioisotopes: ${ }^{133} \mathrm{Ba}$ and ${ }^{137} \mathrm{Cs}$. The com- 157 bination of both emitters generates a gamma energy spectrum 158 whose full energy peaks have centroids and a relationship of 159 areas very similar to the ${ }^{131}$ I spectrum. The simulated ${ }^{131}$ I 160 source has the same area as the impregnated filter. The emitter 161 material is deposited on a polymeric membrane with a stainless 162 steel backing of $0.762 \mathrm{~mm}$ thickness and an $0.9 \mathrm{mg} / \mathrm{cm}^{2}$ alu- 163 minized mylar window. Gamma absorption of the window and 164 the backscattering on the back of the membrane are negligible. 165 Therefore, it can be considered that the material and geometry 166 
Characteristics of THE CALIBRATION SOURCES (REFERENCE FOR ACTIVITY: 01-JANUARY-2014)

(a)

\begin{tabular}{cc}
\hline Nuclides & ${ }^{137} \mathrm{Cs},{ }^{133} \mathrm{Ba}$ \\
${ }^{137} \mathrm{Cs}$ Activity & $0.4096 \mathrm{kBq}$ \\
${ }^{133} \mathrm{Ba}$ Activity & $4.222 \mathrm{kBq}$ \\
${ }^{131}$ I Activity & $3.684 \mathrm{kBq}$ \\
Manufacturer & Eckert \& Ziegeler \\
Model & EAB-131(s)-PL \\
Source No. & K9-928 \\
\hline
\end{tabular}

(b)

\begin{tabular}{cc}
\hline Activity & $3.863 \mathrm{kBq}$ \\
Manufacturer & Eckert \& Ziegeler \\
Model & EAB-060-PL \\
Source No. & K9-925 \\
\hline
\end{tabular}

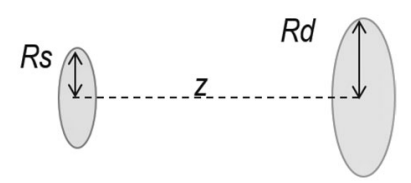

F2:1

of the source have the same behaviour as the impregnated paper filter. To simulate the detector response on the MCNP5 simulation we had used the FWHM obtained from the peaks on the spectra for the calibration sources $\left({ }^{131} \mathrm{I}\right.$ and $\left.{ }^{60} \mathrm{Co}\right)$ with the experimental setup. The function used is:

$$
F W H M=0.008+0.013 \cdot \sqrt{E+0.593 \cdot E^{2}}
$$

where $\mathrm{E}$ is the energy in $\mathrm{MeV}$ and the FWHM obtained is also in $\mathrm{MeV}$.

Experimental efficiencies were obtained by analyzing the experimental spectra of ${ }^{131} \mathrm{I}$ and ${ }^{60} \mathrm{Co}$ by pGamma. Before the calculation of the efficiency, the net counts of the experimental peaks had to be compensated by a correction factor. The source capsule elevated the membrane where the radioactive material is deposited such that the membrane is slightly higher than the paper filter (about $0.283 \mathrm{~cm}$ ). Assuming that both sources, the impregnated paper filter in normal operation and the calibration source, are discs and the detector window is a disc too (geometry on Fig. 2), we could determine the geometric factor in both cases using the following expansion in power series:

$$
\begin{aligned}
g f_{i}= & \frac{1}{2}\left(1-\frac{1}{R}\right)-\frac{3 \cdot \omega^{2} \psi^{2}}{16 \cdot R^{5}} \cdot\left[1-\frac{5 \psi^{2}}{6 \cdot R^{4}} \cdot\left(1-\frac{3 \cdot \omega^{2}}{4}\right)\right. \\
& \left.+\frac{35 \cdot \psi^{4}}{48 \cdot R^{8}}\left(1-\frac{5 \cdot \omega^{2}}{2}+\frac{5 \cdot \omega^{4}}{8}\right)+\cdots\right]
\end{aligned}
$$

the factors $R, \psi$ and $\omega$ are determined as:

$$
\psi=\frac{R_{S}}{z} ; \omega=\frac{R_{d}}{z} ; R=\sqrt{1+\omega^{2}}
$$

where $R_{S}$ is the source radius, $R_{d}$ is the detector radius, $z$ is the distance between the source and the detector. Equation (4) can
TABLE II

EXPERIMENTAL DETECTION EFFICIENCY

\begin{tabular}{ccccc}
\hline Peak & $E_{i}(\mathrm{keV})$ & $N_{i}(\mathrm{cps})$ & $S_{i}(p h / s)$ & $\varepsilon_{d}$ \\
\hline${ }^{131}$ I sim & 53.160 & 57.990 & 88.510 & 0.70319 \\
${ }^{131}$ I sim & 276.390 & 40.801 & 296.150 & 0.14786 \\
${ }^{131}$ I sim & 303.000 & 86.024 & 758.550 & 0.12170 \\
${ }^{131}$ I sim & 356.010 & 184.860 & 2566.500 & 0.017730 \\
${ }^{131}$ I sim & 661.500 & 19.830 & 385.100 & 0.05527 \\
${ }^{60}$ Co & 1173.000 & 108.028 & 3573.290 & 0.03244 \\
${ }^{60}$ Co & 1332.000 & 97.690 & 3579.020 & 0.02929 \\
\hline
\end{tabular}

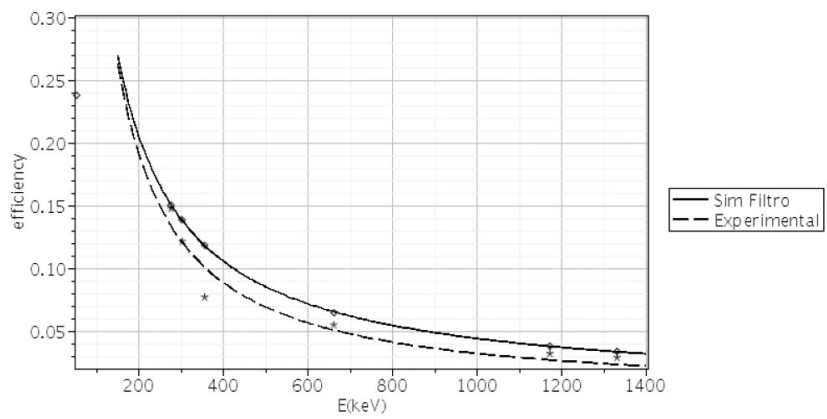

Fig. 3. Curve of efficiency.

be applied either for the calibration source or the impregnated filter. Then the correction factor $c f$ is:

$$
c f=\frac{g f_{\text {calibrationsoruce }}}{g f_{\text {filter }}}
$$

where $g f$ is the geometric factor. With this method, the cor- 190 rection factor is 0.93680. By using seven MCNP5 code sim- 191 ulations, one for each energy, the mean correction factor is 192 0.93184. Efficiency $\varepsilon_{d}$ for energy $E_{i}$ is determined as:

$$
\varepsilon_{d}=\frac{1}{c f} \cdot \frac{N_{i}}{S_{i}}
$$

where $N_{i}$ represents the net count rate of the full energy peak 194 corresponding to the source gamma rays with energy $E_{i}$ and $S_{i} \quad 195$ is the intensity of photons with energy $E_{i}$. Intensity is deter- 196 mined for the two components of the simulated ${ }^{131} \mathrm{I}:{ }^{137} \mathrm{Cs}$ and 197 ${ }^{133} \mathrm{Ba}$, which are treated as two separate sources.

$$
S_{i}=\nu_{i} \cdot A_{i}(0) e^{-T_{t} \cdot \lambda_{i}} ; i={ }^{137} C s,{ }^{133} \mathrm{Ba}
$$

where $\nu_{i}$ is the emission probability of photons with energy $E_{i}, \quad 200$ $A_{i}(0)$ is the activity on the calibration date of the source, $T_{t}$ is 201 the time between the calibration date of the source and the day 202 of the experiment and $\lambda_{i}$ is the disintegration constant. With 203 equations (6) and (7) we find the values of $\varepsilon_{d}$ on Table II. A 204 second efficiency curve, obtained from MCNP5, is compared 205 with that obtained from experimental values, Fig. 3. As can 206 be seen, the two curves are very close, with the exception of 207 experimental efficiency for $380 \mathrm{keV}$. By fitting the experimen- 208 tal points without considering the $380 \mathrm{keV}$ experimental value, 209 efficiency is:

$$
\varepsilon_{d}= \begin{cases}0.43792 & 100 \mathrm{keV} \leq E \leq 200 \mathrm{keV} \\ 60.71703 \cdot E^{-1.07096} & E>200 \mathrm{keV}\end{cases}
$$




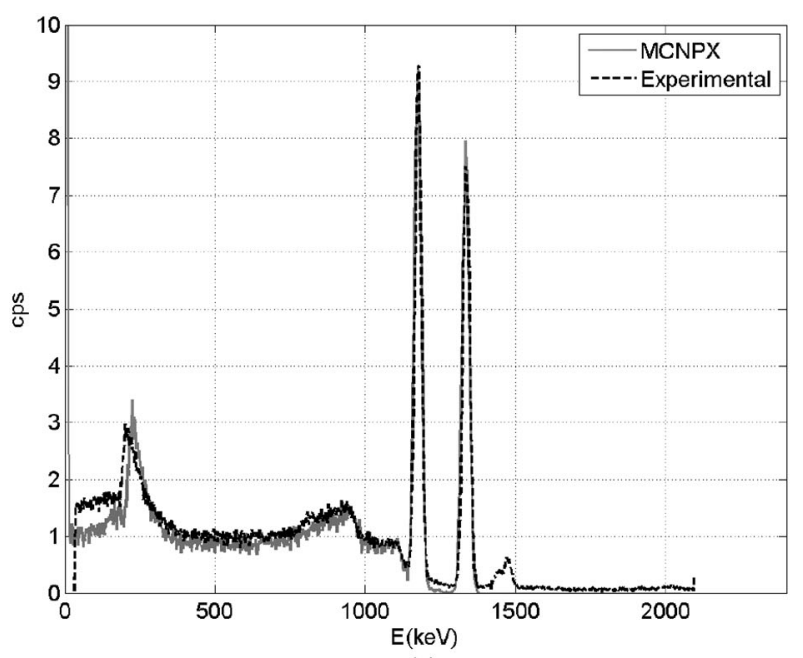

(a)

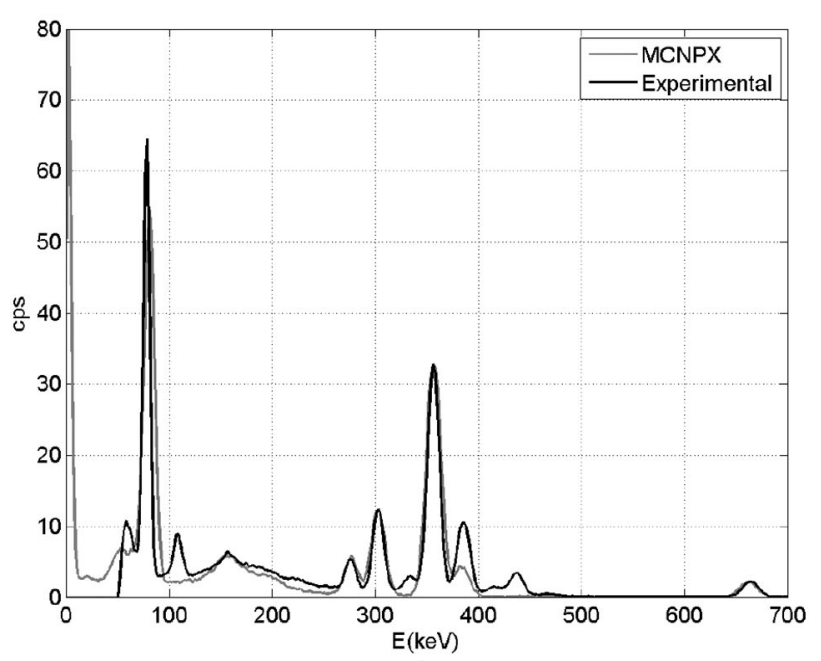

(b)

F4:1 Fig. 4. Comparison between simulated and experimental spectra. Experimental F4:2 setup: $\operatorname{LaBr}_{3} 2^{\prime \prime} \times 2^{\prime \prime}$ scintillator and the DigiBASE compact instrumentation F4:3 from ORTEC. The source is inside the volume of detection equipment for conF4:4 tinuous measurement and identification of gamma radioactivity in aerosols with F4:5 paper filter. (a) Co-60 (b) Simulated I-131.
Since Monte Carlo methods were used to complement the experimental values to obtain the efficiency curve, the equipment simulation model must be benchmarked. In fact, without the geometry correction, Fig. 3 itself could be a validation of the Monte Carlo simulations. It is interesting to analyze and compare the experimental and Monte Carlo simulated spectra of the equipment with the calibration source instead of the paper filter. As the sources were very close to the front window of the detector, some true coincidence summing peaks appeared on the spectrum. These cannot be reproduced with a single MCNP5 simulation, but as we want to compare the procedure used to obtain the efficiency curve and these sum peaks are not required for the efficiency calculations, we will not simulate them. Fig. 4 compares simulated and experimental ${ }^{60} \mathrm{Co}$ and simulated source of ${ }^{131} \mathrm{I}$ spectra. The simulation reproduces perfectly the processes that not depend on the electronic instrumentation modules. As can be seen, backscattering peaks, Compton continuum, Compton valley and two
TABLE III

COMPARISON OF NET COUNTS OF PEAKS

\begin{tabular}{c|cc}
\multicolumn{3}{c}{ Net Counts ${ }^{60}$ Co (cps) } \\
\hline $\mathrm{E}(\mathrm{keV})$ & Experim. & MCNP \\
\hline 1173 & 107.95 & 122.13 \\
1332 & 97.62 & 112.34 \\
\hline
\end{tabular}

\begin{tabular}{c|cc|cc}
\multicolumn{2}{c}{ Net Conts ${ }^{131}$ I (cps) } & Gross counts ${ }^{131}$ I (cps) \\
\hline $\mathrm{E}(\mathrm{keV})$ & Experim. & MCNPX & Experim. & MCNP \\
\hline 60 & 24.11 & 8.60 & 57.99 & 65.19 \\
80 & 189.18 & 303.36 & 260.91 & 380.45 \\
276 & 21.02 & 17.61 & 40.80 & 44.48 \\
303 & 63.31 & 73.27 & 86.02 & 104.65 \\
356 & 184.86 & 249.07 & 231.13 & 291.88 \\
661.5 & 19.83 & 22.51 & 22.32 & 22.79 \\
\hline
\end{tabular}

full energy peaks appear. The differences between both spectra 229 are due to the fact that background radiation is not simulated. 230 Intrinsic radiation from the $\mathrm{LaBr}_{3}(\mathrm{Ce})$ scintillator, i.e. ${ }^{138} \mathrm{La} 231$ and ${ }^{138}$ La plus X-rays peaks at $1468 \mathrm{keV}$, appears in the experi- 232 mental spectrum. This component was not simulated, but is not 233 relevant for efficiency calibration. Moreover, at low energies 234 the simulated spectrum has fewer counts than the experimental 235 one. This is because the Monte Carlo model does not simulate 236 the background radiation components of cosmic rays or earth's 237 NORMs, resulting in fewer X-rays on the lead shielding (peak 238 near $80 \mathrm{keV}$ in the spectrum). In our model, only X-rays from 239 absorption of the calibration source radiation are generated. 240 Again, this is not important for efficiency calculation.

Since the simulated ${ }^{131}$ I has many peaks at low energies, the 242 effect of sum peaks is more noticeable, at least in our energy 243 range (0-2048 keV). Monte Carlo does not generate sum peaks, 244 as can be seen in Fig. 4. For full energy peaks with little or no 245 influence of sum peaks, simulation results are good. Table III 246 compares the net areas of full energy peaks of simulated and 247 experimental spectra. Peaks influenced by a sum peak are not 248 used in efficiency calibration.

\section{Determination of The ACtivity Concentration 250}

After identification of gamma emitters in the spectrum, the 251 spectrometric analysis system determines their specific activity 252 in the air $\tilde{A}_{a}$, expressed in $\mathrm{Bq} / \mathrm{m}^{3}$, according to the net area of 253 the most efficient emitter of the isotope. However, the obtained 254 spectrum corresponds to the number of counts caused by the 255 radionuclide concentration on the filter, which is different from 256 the radionuclide concentration in the air. Because the activity on 257 the filter $A_{f}$ is proportional to the number of captured atoms, 258 a balance of activity can be performed in the same way as for 259 concentration. The radionuclide concentration of an analysed 260 emitter on the filter at a certain time depends on three factors: 261 1) the number of captured atoms of this emitter; 2) decays of 262 the parent nuclei of this emitter, and 3) decays of this emitter. 263

Activity on the filter $A_{f}$ is proportional to activity in the air 264 $\tilde{A}_{a}$, air flow $\mathrm{Q}$, and retention efficiency of the filter $\varepsilon_{f}$ [4], [5]. 265 Nevertheless, as activity on the filter implies a balance of matter 266 on the filter, concentration of each radionuclide depends on its 267 
position in the decay series. In the case of aerosol equipment, the radionuclides are belonging to the ${ }^{238} \mathrm{U}_{-}{ }^{222} \mathrm{Rn}$ series, the ${ }^{232} \mathrm{Th}-{ }^{220} \mathrm{Rn}$ (chiefly ${ }^{212} \mathrm{~Pb},{ }^{212} \mathrm{Bi}$ and ${ }^{208} \mathrm{Tl}$ ) series or to none of the series. A slightly different statement is required for each case.

\section{A. Radionuclides not Belonging to a Series}

Most artificial emitters fall in this category. The balance of matter in this case is simply:

$$
\frac{d A_{f}}{d t}=Q \varepsilon_{f} \tilde{A}_{a}(0)-\lambda_{i} A_{f}
$$

Equation (9) can be solved by integration and as result the filter activity of the emitter analysed is:

$$
A_{f}(t)=\frac{Q \cdot \varepsilon_{f} \cdot \tilde{A}_{a}}{\lambda} \int_{0}^{T} 1-e^{-\lambda t} d t
$$

Then, from Equation (10), the specific activity $\tilde{A}_{a}$ in the air for emitter $i$ (expressed $\mathrm{Bq} / \mathrm{m}^{3}$ ) is:

$$
\tilde{A}_{a}=\frac{\lambda_{i} N_{i} T}{Q \varepsilon_{f} \varepsilon_{d} \nu_{i} \int_{0}^{T}\left(1-e^{-\lambda_{i} t}\right) d t}
$$

Where $\lambda_{i}$ is the decay constant for radionuclide $i, N_{i}$ the net area (counts per second) of the full energy peak of the most probable gamma of radionuclide $i, T$ the detection time (live time fo the Multiple Channel Analyzer), $Q$ the average airflow, $\varepsilon_{f}$ the filter efficiency, $\varepsilon_{d}$ the detection efficiency for the most probable gamma of radionuclide $i$, and $\nu_{i}$ the emission probability of the most probable gamma of radionuclide $i$.

\section{B. ${ }^{238} U-{ }^{222} R n$ Series}

The gamma emitters in the air of interest belonging to the decay series of ${ }^{238} \mathrm{U}$ are the descendents of ${ }^{222} \mathrm{Rn}$ :

$$
{ }^{222} \mathrm{Rn} \stackrel{\alpha}{\longrightarrow}{ }^{218} \mathrm{Po}(1) \stackrel{\alpha}{\longrightarrow}{ }^{214} \mathrm{~Pb}(2) \stackrel{\beta}{\longrightarrow}{ }^{214} \mathrm{Bi}(3)
$$

Numbers in parenthesis in the chain (12) represent the nomenclature used for the radionuclides in the following equations. These radionuclides are present on all countings because they come from the earth and surrounding buildings. Among them we can find some gamma emitters of certain importance, mainly ${ }^{214} \mathrm{~Pb}$ and ${ }^{214} \mathrm{Bi}$. The equations of balance of matter for chain (12) are:

$$
\begin{aligned}
\frac{d A_{f 1}}{d t} & =\tilde{A}_{a 1}(0) Q \varepsilon_{f}-\lambda_{1} A_{f 1} \\
\frac{A_{f 2}}{d t} & =\lambda_{1} A_{f 1}+\tilde{A}_{a 2}(0) Q \varepsilon_{f}-\lambda_{2} A_{f 2} \\
\frac{d A_{f 3}}{d t} & =\lambda_{2} A_{f 2}+\widetilde{A}_{a 3}(0) Q \varepsilon_{d}-\lambda_{3} A_{f 3}
\end{aligned}
$$

${ }^{218}$ Po reaches its equilibrium at $95 \%$ in 13 minutes. By comparing the partial time of detection of $1 \mathrm{~h}$ and the total time of detection of $24 \mathrm{~h}$, the hypothesis that ${ }^{218} \mathrm{Po}$ and ${ }^{214} \mathrm{~Pb}$ are in equilibrium in the air can be supported.

$$
\tilde{A}_{a 1}(0)=\tilde{A}_{a 2}(0)
$$

By considering the equilibrium condition Eq. (14) and devel- 301 oping the balance equations Eq. (13), the specific activities of 302 ${ }^{214} \mathrm{~Pb}$ and ${ }^{214} \mathrm{Bi}$ can be determined by:

$$
\tilde{A}_{a 2}(0)=\frac{1}{2} \frac{N_{2} T \lambda_{2}}{Q \nu_{2} \varepsilon_{f} \varepsilon_{d_{2}} \int_{0}^{T}\left(1-e^{-\lambda_{2} t}\right) d t}
$$

The equation of balance of matter for chain 12 is (for simplicity 304 we omit the explicit time dependences here):

$$
\begin{aligned}
\tilde{A}_{a 3}(0)= & \frac{\lambda_{3} N_{3} T}{Q \nu_{3} \varepsilon_{f} \varepsilon_{d_{3}} \int_{0}^{T}\left(1-e^{-\lambda_{3} t}\right) d t} \\
& -\frac{2 \tilde{A}_{a 2}(0)}{\int_{0}^{T}\left(1-e^{-\lambda_{3} t}\right) d t}\left[\int_{0}^{T}\left(1-e^{-\lambda_{3} t}\right) d t\right. \\
& \left.+\frac{\lambda_{3}}{\lambda_{2}-\lambda_{3}} \int_{0}^{T}\left(e^{-\lambda_{2} t}-e^{-\lambda_{3} t}\right) d t\right]
\end{aligned}
$$

Emission probability $\nu_{i}$, the net area of the full energy peak 306 $N_{i}$ and detection efficiency $\varepsilon_{i}$ correspond to the most probable 307 gamma of the analised radionuclide.

\section{C. ${ }^{232}$ Th- ${ }^{220}$ Rn Series}

As in the previous case, only the nuclides at the end of the 310 chain are of interest in this series, i.e. from ${ }^{220} \mathrm{Rn}$ :

$$
{ }^{220} \mathrm{Rn} \stackrel{\alpha}{\longrightarrow}{ }^{216} \mathrm{Po}(1) \stackrel{\beta}{\longrightarrow}{ }^{212} \mathrm{~Pb}(2) \stackrel{\beta}{\longrightarrow}{ }^{212} \mathrm{Bi}(3) \stackrel{\beta}{34 \%}{ }^{208} \mathrm{Tl}(4)
$$

These radionuclides are always present in air aspiration, like 312 in the previous series. Among them, ${ }^{212} \mathrm{~Pb},{ }^{212} \mathrm{Bi}$ and ${ }^{208} \mathrm{Tl} 313$ are detected by the equipment. ${ }^{212} \mathrm{~Pb}$ bifurcates to ${ }^{208} \mathrm{Tl}$ with 314 $35.94 \%$ and to ${ }^{212}$ Po with $64.06 \%$, but ${ }^{212}$ Po is not an impor- 315 tant $\gamma$ emitter. However, in the location areas of our monitoring 316 stations there are fewer of those than of the ${ }^{238} \mathrm{U}_{-}{ }^{222} \mathrm{Rn}$ series, 317 and in typical spectra generated by the equipment only the pres- 318 ence of ${ }^{212} \mathrm{~Pb}$ is detected. The balance of matter is similar to 319 that of the previous series Eq. 13. The half-life of ${ }^{216} \mathrm{Po}$ is 320 $0.15 \mathrm{~s}$. Hence, it can be assumed that at the end of detection 321 equilibrium exists between ${ }^{216} \mathrm{Po}$ and ${ }^{212} \mathrm{Bi}$.

\section{AnAlysis of ${ }^{131} \mathrm{I}$}

\section{A. Identification and Minimum Detectable Activity (MDA)}

Full energy peaks of ${ }^{131}$ I gamma emitters are very close 325 to some full energy peaks of ${ }^{212} \mathrm{~Pb},{ }^{214} \mathrm{~Pb}$ and ${ }^{214} \mathrm{Bi}$. These 326 natural emitters belong to the ${ }^{222} \mathrm{Rn}$ radon and ${ }^{220} \mathrm{Rn}$ thoron 327 series, and are always present in the spectrum. Overlapping 328 of iodine gamma lines with other emmiters occurs between 329 the $284.2 \mathrm{keV}, 364.4 \mathrm{keV}$ and $636.97 \mathrm{keV}$ peaks of ${ }^{131} \mathrm{I} . \quad 330$ The $722.89 \mathrm{keV}$ peak does not overlap with those of natu- 331 ral emitters, but it has very low emission probability. Like the 332 $80.18 \mathrm{keV}$ of ${ }^{131} \mathrm{I}$, that does not overlap with other peaks, but is 333 outside the linear operating range of the scintillator. Therefore, 334 to identify ${ }^{131}$ I we can only use full energy peaks overlapped 335 with natural emitter peaks, which are always present in the 336 


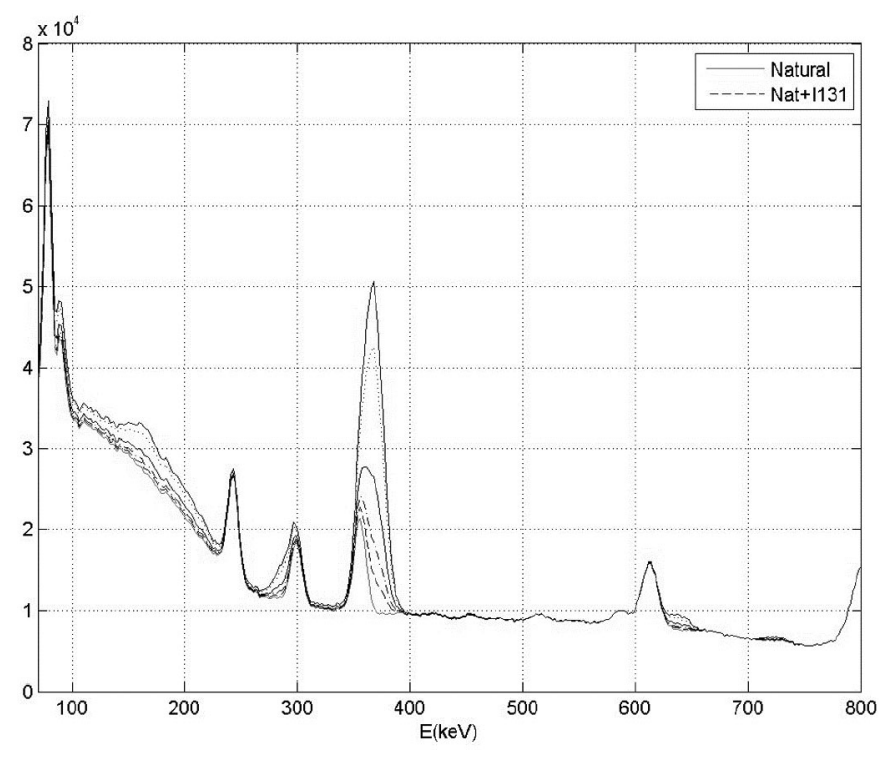

F5:1 Fig. 5. Spectra of ${ }^{131}$ I. Obtained by a combination of experimental backF5:2 ground and simulations with the filter impregnated with ${ }^{131} \mathrm{I}$. The different F5:3 lines represents the spectra for different concentrations of ${ }^{131} \mathrm{I}$. spectrum. As a consequence, the minimum detectable activity of ${ }^{131} \mathrm{I}$ is greater than for other emitters.

Identification of ${ }^{131}$ I was accomplished using several equipment simulations where the filter was impregnated with ${ }^{131} \mathrm{I}$. These simulated spectra was combined with an experimental background spectrum. The resultant spectra is shown in Fig. 5 When the $364.4 \mathrm{keV}$ peak is identified as ${ }^{131} \mathrm{I}$ instead of ${ }^{214} \mathrm{~Pb}$ in the combined spectrum analised by pGamma, the activity of ${ }^{131}$ I ranges between $0.4 \mathrm{~Bq} / \mathrm{m}^{3}$ and $0.8 \mathrm{~Bq} / \mathrm{m}^{3}$. The latter is its Minimum Detectable Activity (MDA). For comparison, ${ }^{60} \mathrm{Co}$ MDA is $0.02402 \mathrm{~Bq} / \mathrm{m}^{3}$ and ${ }^{137} \mathrm{Cs}$ MDA is $0.01662 \mathrm{~Bq} / \mathrm{m}^{3}$ (the air flow for the experimental background spectrum was $\left.8.870 \mathrm{~m}^{3} / \mathrm{h}\right)$.

\section{B. Determination of Specific Activity}

The activity concentration of ${ }^{131}$ I can be determined using the filter' s retention efficiency, which has already been studied by several authors ([4], [5]). It depends on the iodine species, particle size and air flow. The equipment for continuous measurement and identification of gamma radioactivity in aerosols for which this version of the pGamma code has been developed uses a GF 10 from Hahnemühle fiberglass paper filter. The fiberglass paper filter can only retain iodine particles. Their average size can be found in a number of works [6], [7]. Their diameter typically ranges between $0.2 \mu \mathrm{m}$ and $0.5 \mu \mathrm{m}$. The air flow of the equipment in normal operation is $110 \mathrm{~m}^{3} / \mathrm{h}$. In these conditions, the efficiency of the GF 10 filter for iodide can be considered as:

$$
\varepsilon_{f}=\left\{\begin{array}{l}
99-0 \%(\text { for particles }) \\
0 \%(\text { for all the other cases })
\end{array}\right.
$$

However, the estimation of filter efficiency is not enough to determine the activity concentration of ${ }^{131} \mathrm{I}$. Iodine can appear as a particle or gas in the form of elemental $\mathrm{I}_{\text {or }} \mathrm{I}^{2}$, organic 366 (chiefly methyl iodide $\mathrm{CH}^{3} \mathrm{I}$ ) or inorganic (hypoiodous HOI). 367 The GF 10 filter does not capture all iodine species (actu- 368 ally, no filter does); it only retains particles. The only way 369 to determine total activity concentration in the air is to know 370 the concentration of iodine particles at the surveillance sta- 371 tion, but this is impossible because of the special behavior of 372 iodine transport in the atmosphere. The composition of iodine 373 can be measured by gas chromatography [8], but this method 374 is outside the equipment's concept. Several authors have made 375 estimates from information collected during the Chernobyl or 376 Fukushima accidents. For example, in [9] it was estimated that 377 $50 \%$ of iodine is particles and the rest is gaseous. In his book 378 [10], A. C. Chamberlain reports some particle-gas rate val- 379 ues, but they differ significantly from each other. Finally, the 380 assumption in RASCAL 4.3 code [11], i.e. $33 \%$ of iodine par- 381 ticles, was considered for this work. We must bear in mind that 382 the final purpose of the equipment is not to perform accurate 383 measurements of air component concentration, but to provide 384 information about gamma emitters in the air, such as the above 385 estimates.

\section{Action LeVEls}

Three action levels are provisionally considered ${ }^{2}$ :

1) Investigation level.

2) Alert level, according to the concentration limit value in 390 the air for public members (concentration giving by a 391 dose $1 \mathrm{mSv} /$ year).

3) Alarm level, according to twice the concentration limit 393 value for the public.

The investigation level is initiated when:

1) The activity detected exceeds activity concentration 396 thresholds for critical anthropogenic or natural isotopes 397 stored in a library. For the former, the threshold is 398 based on the recommendation of the 18 December 2003399 Commission, (2004/2/EURATOM) DO L2/36 (6.1.2004). 400 For NORM radionuclides, the threshold is based on sta- 401 tion measurement values (e.g. $2 \cdot 10^{-2} \mathrm{~Bq} / \mathrm{m}^{3}$ for ${ }^{131} \mathrm{I} 402$ and $3 \cdot 10^{-2} \mathrm{~Bq} / \mathrm{m}^{3}$ for $\left.{ }^{137} \mathrm{Cs}\right)$.

2) The analysis report contains one or more unidentified 404 peaks.

3) The variation of the total number of counts on the detec- 406 tor during consecutive identical periods of time, defined 407 as Relative Variation in the Number of Counts (RVC), 408 exceeds an empirical value. This can be expressed as:

$$
\frac{d C}{C}=\frac{C\left(t_{2}\right)-C\left(t_{1}\right)}{C\left(t_{1}\right)}
$$

Where $C\left(t_{1}\right)$ and $C\left(t_{2}\right)$ are the number of counts on two 411 consecutive identical periods of time. After a year of operation 412 we propose a statistic analysis of the results and a revision of 413 the investigation levels.

${ }^{2}$ Provided by the Spanish "Consejo de Seguridad Nuclear" (Nuclear Security Council) 


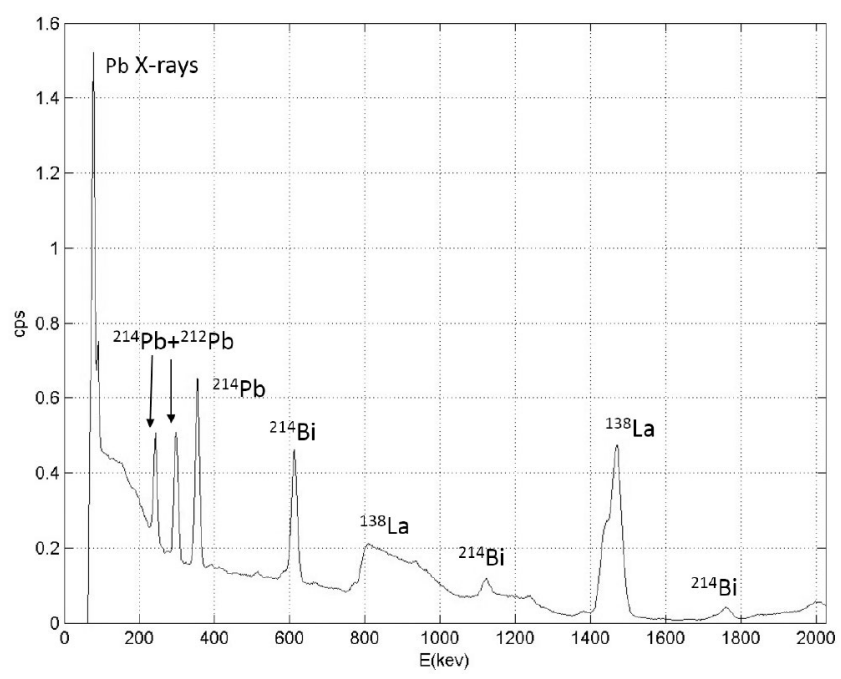

F6:1
Fig. 6. Spectrum analised, obtained with the equipment for continuous measurement and identification of gamma radioactivity in aerosols with paper filter $\left(2^{\prime \prime} \times 2^{\prime \prime} \mathrm{LaBr}_{3}\right.$ scintillator with digiBASE form ORTEC).

TABLE IV

DETECTABLE NORM GAMMA EMITTERS FROM AERSOLS [12]

\begin{tabular}{|c|c|c|}
\hline Emitter & Series & Gammas emitted (keV) \\
\hline${ }^{214} \mathrm{~Pb}$ & ${ }^{238} \mathrm{U}_{-}{ }^{222} \mathrm{Rn}$ & $\begin{array}{c}242(7.2 \%), 295.22(18.5 \%), 351.93 \\
(35.6 \%)\end{array}$ \\
\hline${ }^{214} \mathrm{Bi}$ & ${ }^{238} \mathrm{U}^{222} \mathrm{Rn}$ & $\begin{array}{c}609.31(45.49 \%), 1120.29(14.09 \%), \\
1764.49(15.28 \%), 1847.42(2 \%) 2204.21 \\
(4.9 \%)\end{array}$ \\
\hline${ }^{212} \mathrm{~Pb}$ & ${ }^{232} \mathrm{Th}^{220} \mathrm{Rn}$ & $238.63(43.6 \%), 300.09(3.18 \%)$ \\
\hline${ }^{212} \mathrm{Bi}$ & ${ }^{232} \mathrm{Th}^{220} \mathrm{Rn}$ & $727.33(6.74 \%), 1620.74(1.51 \%)$ \\
\hline${ }^{208} \mathrm{Tl}$ & ${ }^{232} \mathrm{Th}-{ }^{220} \mathrm{Rn}$ & $\begin{array}{c}510.7(6.29 \%), 583.19(30.6 \%), 2614.51 \\
(35.85 \%)\end{array}$ \\
\hline
\end{tabular}

\section{Analysis of a Spectrum by PGamma}

This section presents a pGamma analysis example of a typical $24 \mathrm{~h}$ spectrum obtained at Ascó station on 10 January 2015. The average air flow was $8.35 \mathrm{~Bq} / \mathrm{m}^{3}$, there was no rainfall and the temperature ranged between $7^{\circ} \mathrm{C}$ and $15^{\circ} \mathrm{C}$. The spectrum is shown in Fig. 6. Note that the peaks caused by NORM, i.e. detectable gamma emitters of the ${ }^{238} \mathrm{U}$ series and ${ }^{212} \mathrm{~Pb}$ of the ${ }^{232} \mathrm{Th}$ series, appear combined with the intrinsic spectrum of the $\mathrm{LaBr}_{3}$ detector. No anthropogenic emitters are observed in the air.

Considering the spectrum in Fig. 6, the components are: 1) Aerosols (mainly NORM) retained on the filter; 2) Cosmic particles and their interaction with elements on the detection zone and 3) Intrinsic spectrum of the detector. Table IV illustrates the detectable gamma peaks of the ${ }^{238} \mathrm{U}$ and ${ }^{232} \mathrm{Th}$ series. Fig. 7 shows the background spectrum (without air suction or aerosol retention) generated by the equipment. The cosmic component is only important at low energies. The level of intrinsic radiation from the detector is very significant in the range of interest, even higher than for the component resulting from aerosols retained on the filter. The radiation generated in the $\mathrm{LaBr}_{3}$ crystal is mainly due to ${ }^{138} \mathrm{La}$ (Fig. 8). The most important peaks of the intrinsic spectrum of the $\mathrm{LaBr}_{3}$

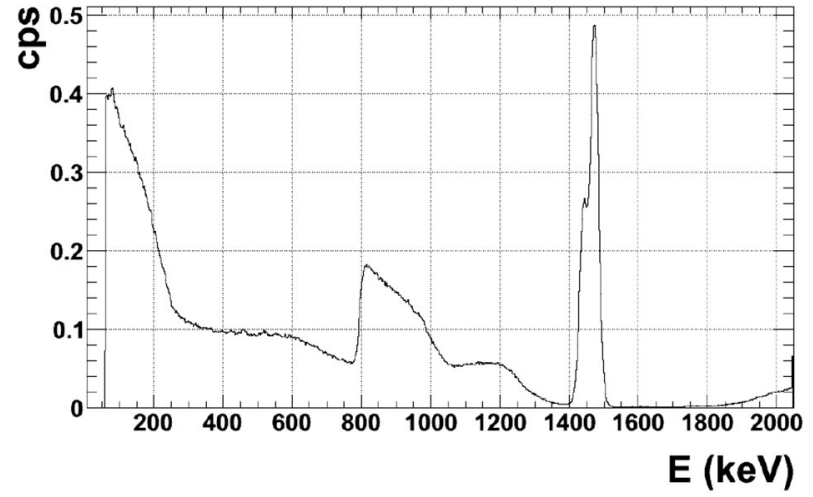

Fig. 7. Background spectrum of the equipment of the measurement of gamma F7:1 radiation on aerosols by paper filter.

F7:2

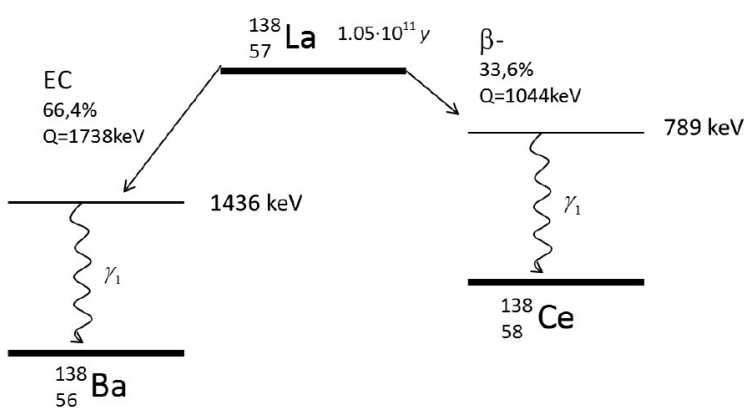

Fig. 8. Decay scheme for ${ }^{138} \mathrm{La}$ [13].

F8:1

scintillation detector are: 1 ) between $(0-300) \mathrm{keV} \beta$ continuous; 438 2) between (700-1100) $\mathrm{keV} \beta$ continuous plus gammas of 439 $789 \mathrm{keV}$; 3) between (1400-1500) keV gammas of $1436 \mathrm{keV} 440$ and a sum peak of gammas of $1436 \mathrm{keV}$ and X-rays of $32 \mathrm{keV} . \quad 441$

Fig. 9 shows the pGamma report of the analised spectrum. 442 The report has four parts: 1) overall parameters of the spec- 443 trum; 2) specific activity of identified isotopes (first column for 444 activity, second for error and third for the minimum detectable 445 activity); 3) identified peaks; and 4) unidentified peaks. $\quad 446$

Following the list of expected peaks (Table IV), the code 447 identified: 1) The most probable ${ }^{214} \mathrm{~Pb}$ peaks; 2) The most prob- 448 able ${ }^{214} \mathrm{Bi}$ peaks; 3) One ${ }^{212} \mathrm{~Pb}$ peak; and 4) The $789 \mathrm{keV}$ and 449 of $1436 \mathrm{keV} \gamma$ peaks and the combination of the $\gamma$ of $1436 \mathrm{keV} \quad 450$ with the X-ray of $32 \mathrm{keV}$ of the intrinsic spectrum of the $\mathrm{LaBr}_{3} \quad 451$ crystal. ${ }^{212} \mathrm{Bi}$ does not appear in the list of identified peaks 452 because its gamma rays have a very low emission probability 453 and its full energy peaks are not significant enough. ${ }^{208} \mathrm{Tl}$ has no 454 identified peaks. From ${ }^{208} \mathrm{Tl}$, the $510.7 \mathrm{keV}$ peak is very close 455 to the annihilation peak and is too small to be distinguished by 456 a scintillator, the same is true of the $583.19 \mathrm{keV}$ peak. This one 457 is important but very close to the $609.31 \mathrm{keV}$ peak of ${ }^{214} \mathrm{Bi}, \quad 458$ which is a very significant one, and therefore the overlapping 459 peak is assigned to ${ }^{214} \mathrm{Bi}$. The $2614.51 \mathrm{keV}$ peak is out of the 460 operating range of the equipment. It must be remembered that, 461 with the resolution of scintillators, the $242 \mathrm{keV}$ and $295.22 \mathrm{keV} \quad 462$ peaks of ${ }^{214} \mathrm{~Pb}$ coincide with the ${ }^{212} \mathrm{~Pb}$ peaks. Finally, the peak 463 6 at $514.1 \mathrm{keV}$ is the annihilation peak. 
[1]

11640368

10179770

[2]

pb212 SerieTh232Rn220 3.15e-0013.56e-003 6.98e-0031

bi214 Serieu238Rn222 $1.42 e+001 \quad 8.05 e-002 \quad 2.88 e-001710 \quad 11$

$\begin{array}{llll}12 & 13 & 17 & 18\end{array}$

pb214 SerieU238Rn222 1.49e+001 7.23e-002 1.47e-001 23 [3]

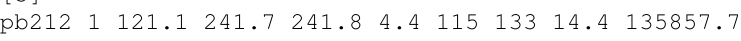

SerieTh232Rn220

bi214 $7307.0 \quad 611.0 \quad 609.6 \quad 9.6 \quad 286 \quad 326 \quad 20.9 \quad 302812.7$ SerieU238Rn222

bi214 $10 \quad 467.6 \quad 932.4 \quad 936.5 \quad 5.4 \quad 464 \quad 479 \quad 18.4 \quad 5440.6$ SerieU238Rn222

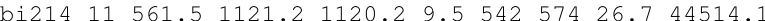

SerieU238Rn222

bi214 $12 \quad 618.1 \quad 1235.2 \quad 1238.1 \quad 6.3 \quad 612 \quad 667 \quad 23.1 \quad 8134.9$

SerieU238Rn222

bi214 $13 \quad 690.1 \quad 1380.9 \quad 1375.5 \quad 7.1 \quad 676 \quad 695 \quad 19.7 \quad 4868.6$

SerieU238Rn222

bi214 $17 \quad 876.3 \quad 1759.3 \quad 1753.0 \quad 17.6 \quad 846 \quad 894 \quad 33.7 \quad 51719.2$ SerieU238Rn222

bi214 $18921.8 \quad 1852.1 \quad 1841.19 .9902927 \quad 30.14166 .6$ SerieU238Rn222

$\begin{array}{llllllllll}\text { pb214 } & 2 & 148.9 & 296.7 & 296.9 & 4.8 & 142 & 158 & 17.3 & 178632.9\end{array}$ SerieU238Rn222

pb214 $3 \quad 177.6 \quad 353.5 \quad 353.4 \quad 5.5 \quad 168 \quad 186 \quad 14.1 \quad 304242.5$

SerieU238Rn222

anig $6 \quad 257.8 \quad 512.9 \quad 514.1 \quad 5.3 \quad 252 \quad 266 \quad 17.0 \quad 7653.3$ Pic

$\mathrm{d}^{\prime}$ aniquilació

$\begin{array}{lllllllllll}\text { la138 } & 9 & 405.2 & 807.1 & 818.3 & 19.8 & 391 & 438 & 52.7 & 172130.3\end{array}$

Intrinsec

la138 $14 \quad 733.3 \quad 1468.4 \quad 1468.6 \quad 7.8 \quad 723 \quad 780 \quad 21.9 \quad 229245.5$

Intrinsec

[4]

F9:1 Fig. 9. Report with the analysis of pGamma.
The pGamma code is an automatic spectrometric analysis system for environmental radiation monitoring equipment with spectrometric capability. The version presented in this paper was specifically designed for our equipment of continuous measurement and identification of gamma radioactivity in aerosols with paper filter. Nevertheless, the code is perfectly adaptable to other equipment of the environmental radiological surveillance network of the local Catalan Government. The code identifies gamma emitters in the energy spectrum and determines their specific activity. If an emitter is not identified or activity concentration of any identified emitter exceeds an empirical threshold, an alarm is generated.

\section{REFERENCES}

[1] A. Savitzky and M. Golay, "Smoothing and differentiation of data by sim- 479 plified least squares procedures," Anal. Chem., vol. 36, pp. 1627-1639, 480 1964.

[2] E. Browne and R. Firestone, Table of Radioactive Isotopes, S. Shirley, 482 Eds. New York, NY, USA: Wiley, 1986.

[3] S. Organizations, Multi-Agency Radiological Laboratory Analytical 484 Protocols Manual (MARLAP). Cap 15 Quantification of Radionuclides. 485 NUREG-1576 / EPA 402-B-04-001A / NTIS PB2004-105421, 486 United States Environmental Protection Agency et. al., Jul. 2004, 487 http://www.epa.gov/radiation/marlap/manual.html 488

[4] W. John and G. Reischl, "Measurements of the filtration efficiencies of 489 selected filter types," Atmospher. Environ., vol. 12, pp. 2015-2019, 1978. 490

[5] E. Kitto and D. Anderson, "Correspondence. the use of whatman-41 491 filters for particle collection," Atmospher. Environ., vol. 22, no. 11, 492 pp. 2629-2630, 1988. tive particles collected at tokai, japan 6 days after the nuclear accident," 495 J. Environ. Radioact., vol. 132, pp. 1-7, 2014.

[7] E. Bondietti, J. Brantley, and C. Rangarajan, "Size distributions and 497 growth of natural and chernobyl-derived submicron aerosols in ten- 498 nessee," J. Environ. Radioact., vol. 6, pp. 99-120, 1988.

[8] M. Naritomi, Y. Yoshida, and S. Fukuda, "Method for improving the col- 500 lecting performance of iodine samplers under high relative humidity," J. 501 Nucl. Sci. Technol., vol. 10, no. 5, pp. 292-300, 1973.

[9] S. MacMullin, G. Giovanetti, M. Green, R. Henning, R. Holmes, 503 K. Vorren, and J. Wilkerson, "Measurement of airborne fission products 504 in Chapel Hill, NC, USA from the Fukushima Daiichi reactor accident," 505 J. Environ. Radioact., vol. 112, pp. 165-170, 2012.

[10] A. Chamberlain, Radioactive Aerosols, 1st Cambridge, U.K.: Cambridge 507 Univ. Press, 1991.

[11] J. Ramsdell Jr., "Rascal 4.3. dispersion and deposition models," Proc. 509 18th Annu. George Mason Univ. Conf. Atmospheric Transport and 510 Dispersion Modelling, 2014.

[12] G. Gilmore, Practical Gamma-Ray Spectrometry, Hoboken, NJ, USA: 512 Wiley, 2008, http://books.google.es/books?id=mNHvAAAAMAAJ 513

[13] Scintillation products, Tech. note, Brillance Scintillators Performance 514 Summary, Saint Gobain Crystals Tech. Rep., 2009. 